\title{
Fünftes Kapitel: Rahmenbedingungen der Wiedergutmachung in der Frühzeit der Bundesrepublik Deutschland
}

\section{Vergleich der rechtlichen Entwicklung in der britischen und französischen Zone mit der US-Zone}

Die Gründung der Bundesrepublik im Sommer 1949 markiert einen wichtigen Einschnitt in der Entwicklung der Wiedergutmachung. Dies betrifft zunächst einmal den rechtlichen Aspekt. Während die Durchführung der noch in der Besatzungszeit getroffenen Regelungen gerade allmählich anlief, setzten zugleich schrittweise Tendenzen zur Vereinheitlichung der bisherigen Länderregelungen sowie zur Regelung neuer, bislang offen gebliebener Fragen auf Bundesebene ein. Bisher war diese Entwicklung in jeder Zone weitgehend isoliert verlaufen, und selbst innerhalb dieser bestand nur zum Teil Einheitlichkeit. Beispiele für überzonale Regelungen bis dahin sind rar. $\mathrm{Zu}$ erwähnen wäre allenfalls die Einbeziehung von Opfern des Nationalsozialismus in das Soforthilfegesetz des Vereinigten Wirtschaftsgebietes ${ }^{1}$ sowie ein ebenfalls dort erlassenes Gesetz über die Regelung der Ansprüche der Verfolgten in der Sozialversicherung ${ }^{2}$. So zog eine Übersicht über die Wiedergutmachung in der Bundesrepublik aus dem Bundesfinanzministerium 1950 das Fazit, „daß die geltende Gesetzgebung an Buntscheckigkeit und Uneinheitlichkeit kaum zu übertreffen ist ${ }^{\text {“ } 3}$.

Bislang stand die Entwicklung in der US-Zone im Mittelpunkt dieser Arbeit. Wie sah aber die parallele Entwicklung in der britischen und französischen Zone aus? Unterschieden sich die dort geschaffenen Strukturen grundlegend von denen der US-Zone? Und welche Erklärungen lassen sich für die getrennte Entwicklung in den einzelnen Zonen geben?

\section{Britische Zone}

Auch in der britischen Zone gab zunächst die Militärregierung den Ton in der Frage der Behandlung der ehemaligen Verfolgten des Nationalsozialismus an. Am 4. Dezember 1945 erließ sie für alle Länder ihrer Zone die Zonenpolitische Anweisung (ZPA) Nr. 20, in der Sondervergünstigungen bei der Lebensmittelversorgung, bei der Arbeitsplatzund Wohnungsbeschaffung sowie finanzielle Hilfen zugunsten rassisch, religiös und politisch Verfolgter angeordnet wurden. Die Anordnung bezweckte keinen „Ausgleich

1 Zum Soforthilfegesetz vgl. Drittes Kapitel, S. 143.

2 Gesetz über die Behandlung der Verfolgten des Nationalsozialismus in der Sozialversicherung, in: Gesetzblatt der Verwaltung des Vereinigten Wirtschaftsgebietes, Nr. 31, 27. 8. 1949, S. 263 f. Dort wurde die Anrechnung der Verfolgungszeiten als Ersatzzeiten in der Kranken- und Rentenversicherung geregelt.

3 Vormerkung von Friedrich Kuschnitzky, 12.5. 1950, BA, B 126/12523. 
für erlittenes Unrecht", sondern eine "Gratifikation, die den ehemaligen Häftlingen einen besseren Lebensstandard ermöglichen" sollte. Ähnlich wie in der US-Zone zielten auch hier die ersten Schritte auf die Fürsorge und Rehabilitierung der ehemaligen Verfolgten. Bemerkenswert war jedoch ein zusätzlicher pädagogischer Impuls: Der „deutschen Öffentlichkeit" sollte vor Augen geführt werden, „daß demjenigen, der als Gegner des Nationalsozialismus gelitten hat, angemessene Anerkennung gezollt wird $^{\text {“4 }}$. Da die erlittene Verfolgung auf diese Weise moralisch positiv bewertet wurde, war es wiederum konsequent, daß hier die Betreuung der aus kriminellen Gründen Inhaftierten explizit ausgeschlossen war.

Seit Ende 1945 berieten die Länder der britischen Zone über ein zoneneinheitliches Entschädigungsgesetz, doch setzte sich schließlich sowohl bei der britischen Militärregierung als auch im Zonenbeirat der britischen Zone die Aufassung durch, daß ein entsprechender Schritt den einzelnen Ländern überlassen bleiben sollte ${ }^{5}$. Dabei setzte sich Nordrhein-Westfalen an die Spitze der Entwicklung. Am 5. März 1947 beschloß der dortige Landtag ein Gesetz über die Gewährung von Unfall- und Hinterbliebenenrenten an die Opfer der Nazi-Unterdrückung ${ }^{6}$, das auch einer entsprechenden Regelung in Hamburg als Vorbild diente: Am 28. April stimmte die Hamburger Bürgerschaft einem Sonderhilfsrentengesetz zu. Durch diese Regelungen erhielten rassisch, religiös und politisch Verfolgte Rentenansprüche für Schäden an Körper, Gesundheit oder Leben auf der Grundlage der gesetzlichen Unfallversicherung ${ }^{7}$. Ähnliche Regelungen folgten im Verlauf dieses Jahres in Niedersachsen und Schleswig-Holstein ${ }^{8}$. Auch das nordrhein-westfälische Haftentschädigungsgesetz vom 11. Februar 1949, das Verfolgte des Nationalsozialismus ähnlich wie in der US-Zone mit $150 \mathrm{DM}$ pro Haftmonat entschädigen wollte, besaß Vorbildcharakter für die britische Zone. Im Juli folgten Hamburg, Niedersachsen und Schleswig-Holstein diesem Beispiel' ${ }^{9}$. Damit existierten in der britischen Zone zwar Regelungen für die Haftentschädigung, jedoch keine umfassenden Entschädigungsregelungen für Gesundheits- und Existenzschäden, wie sie im Entschädigungsgesetz der US-Zone festgelegt wurden. Deshalb war die britische Zone im Hinblick auf die Entschädigung zunächst auch das Sorgenkind der Bundesrepublik.

4 Nils Asmussen, Der kurze Traum von der Gerechtigkeit. „Wiedergutmachung“ und NS-Verfolgte in Hamburg nach 1945, Hamburg 1987, S.27f. Vgl. dazu auch „Die Wiedergutmachung für die Opfer der nationalsozialistischen Verfolgung in Hamburg“, hrsg. v. Senat der Freien und Hansestadt Hamburg, Hamburg 1960, S. $12 \mathrm{f}$.

5 Vgl. Asmussen, Der kurze Traum, S. 45f.

${ }^{6}$ Gesetz- und Verordnungsblatt (GVOBl) Nordrhein-Westfalen, Nr. 32 v. 24.12. 1947, S. $225 \mathrm{ff}$. Vgl. auch Ernst Féaux de la Croix, Vom Unrecht zur Entschädigung: Der Weg des Entschädigungsrechts, in: Féaux de la Croix u. Helmut Rumpf, Der Werdegang des Entschädigungsrechts unter national- und völkerrechtlichem und politologischem Aspekt, München 1985, S. 26.

7 Vgl. Amussen, Der kurze Traum, S. 49-52. Rolf Theis kehrt die Kausalität gerade um. Vgl. ders., Wiedergutmachung zwischen Moral und Interesse. Eine kritische Bestandaufnahme der deutsch-israelischen Regierungsverhandlungen, Frankfurt a.M. 1989, S. 44.

${ }^{8}$ Gesetz über die Gewährung von Sonderhilfe für Verfolgte der nationalsozialistischen Gewaltherrschaft (Personenschadengesetz) v. 22.9. 1948, in: Niedersächsisches GVOBl, Nr. 23, 1948, S. 77; Gesetz über die Gewährung von Renten an die Opfer des Nationalsozialismus, 4. 3. 1948, in: GVOBl für Schleswig-Holstein, Nr. 10, 1.6. 1948, S. 74 ff. Vgl. auch Féaux de la Croix, Vom Unrecht zur Entschädigung, S. 25 f. u. $30 \mathrm{f}$.

9 Hamburg: Gesetz über die Entschädigung für Freiheitsentziehung aus politischen, weltanschaulichen, religiösen oder rassischen Gründen (Haftentschädigungsgesetz) v. 16.8. 1949, in: GVOBl, Nr. 34, 18. 8. 1949, S. 165167; Niedersachsen: Gesetz über die Entschädigung für Freiheitsentziehung durch Maßnahmen der nationalsozialistischen Gewaltherrschaft (Haftentschädigungsgesetz) v. 31.7. 1949, in: GVOBl, Nr.71, 6.8. 1949, S. 185 f.; Schleswig-Holstein: Haftentschädigungsgesetz, 4.7. 1949, in: GVOBI, Nr. 21, 21.8. 1949, S. 161 f. Vgl. auch Féaux de la Croix, Vom Unrecht zur Entschädigung, S. 23f., 26f. u. 31; Asmussen, Der kurze Traum, S. 54-60. 
Bei der Rückerstattung wiederauffindbaren Eigentums hingegen, die auch in der britischen Zone als selbständiger Bereich abgetrennt wurde, kam es zu einer zoneneinheitlichen Regelung, indem hier die britische Militärregierung am 12. Mai 1949, eineinhalb Jahre nachdem in der amerikanischen und französischen Zone bereits ein derartiges Gesetz in Kraft getreten war, das Militärregierungsgesetz Nr. 59 verkündete. Dabei handelte es sich um eine vereinfachte Fassung des US-zonalen Rückerstattungsgesetzes, womit die Amerikaner schließlich einen Teilerfolg bei der Verfolgung ihres Ziels, die Briten zur Übernahme ihrer eigenen Regelung zu bewegen, erreicht hatten ${ }^{10}$. Die deutsche Seite, die zuvor selbst an einer Rückerstattungsregelung gearbeitet hatte - die Entwürfe wurden allerdings von Walter Schwarz als beschämend qualifiziert ${ }^{11}$-, war an der Formulierung dieses Gesetzes nicht beteiligt worden ${ }^{12}$.

Man kann also zusammenfassend feststellen, daß ähnlich der amerikanischen Militärregierung auch die britische anfänglich bedeutenden Anteil an den Maßnahmen zur Fürsorge und Entschädigung der Verfolgten des Nationalsozialismus in ihrer Zone hatte. Doch bremste die britische Politik wiederholt die weitere Entwicklung. Die politischen Rückwirkungen des Palästina-Konflikts, aber auch die finanzielle Schwäche Großbritanniens nach dem Krieg, die eine gewisse Zurückhaltung, der eigenen Besatzungszone Belastungen aufzuerlegen, erforderlich machte, entwickelten hier eine retardierende Wirkung auf alle Initiativen zum weiteren Ausbau der Wiedergutmachung, wie besonders am Beispiel Hamburgs untersucht worden ist ${ }^{13}$.

\section{Französische Zone}

Die französische Zone war in dieser Hinsicht erfolgreicher, auch wenn hier die Anfänge der Fürsorge und Wiedergutmachung für Verfolgte des Nationalsozialismus aufgrund der territorialen Neugliederungen und Zersplitterung besonders uneinheitlich waren. Wiederum gaben die Vorgaben der Besatzungsmacht wichtige Impulse. Bereits am 8. September 1945 ordnete die französische Militärregierung in Baden die Einrichtung von Betreuungsstellen für Opfer des Nationalsozialismus an ${ }^{14}$. Darunter fielen alle im Zuge der nationalsozialistischen Verfolgung Inhaftierten und ihre Angehörigen. Ziel war ähnlich wie bei den entsprechenden Maßnahmen in den anderen Zonen vor allem die Fürsorge für notleidende Verfolgte. Derartige Anstrengungen unternahmen alle Länder und Landesverwaltungen der französischen Zone, wobei Rheinland-Pfalz nach seiner Gründung Ende August 1946 eine Schrittmacherrolle übernahm ${ }^{15}$.

Im Frühjahr 1946 begannen auch in der französischen Zone koordinierte deutsche

10 Siehe zu diesen Bemühungen etwa General George P. Hays (OMGUS) an Department of Army for CSUSA for CSCAD, 30.12. 1948, IfZ-Archiv, MF 260, OMGUS, AG 1948/185/1.

11 Vgl. Walter Schwarz, Rückerstattung nach den Gesetzen der Alliierten Mächte, München 1974, S.64f.

12 Vgl. ebenda; Amussen, Der kurze Traum, S. $47 \mathrm{f}$.

13 Vgl. Ursula Büttner, Not nach der Befreiung. Die Situation der deutschen Juden in der britischen Besatzungszone 1945 bis 1948, in: Das Unrechtsregime. Internationale Forschung über den Nationalsozialismus, Bd. 2: Verfolgung - Exil - Belasteter Neubeginn, hrsg. v. Ursula Büttner, Hamburg 1986, S. 380f., 387-397; Asmussen, Der kurze Traum; Theis, Wiedergutmachung zwischen Moral und Interesse, S. 44-59.

14 Amtsblatt der Militärregierung Baden, Französisches Besatzungsgebiet, Nr. 8, 4.10. 1945, S. 18 f. Vgl. auch Féaux de la Croix, Vom Unrecht zur Entschädigung, S. 17; Rainer Hudemann, Anfänge der Wiedergutmachung. Französische Besatzungszone 1945-1950, in: Geschichte und Gesellschaft 13 (1987), S. 187.

$15 \mathrm{Vgl}$. Hudemann, Anfänge der Wiedergutmachung, S. 197. Eine Übersicht über die zahlreichen Regelungen in der französischen Zone findet sich bei Féaux de la Croix, Vom Unrecht zur Entschädigung, S. 17ff., 27-30, $32-37,58 \mathrm{ff}$ 
Planungen zur Regelung von Rückerstattung und Entschädigung auf Zonenebene. Hieraus ging der sogenannte „Koblenzer Entwurf“ hervor, der Rückerstattung und Entschädigung zunächst gemeinsam behandelte und der - zwischenzeitig mehrfach überarbeitet - bis Ende 1948 in der Diskussion eine Rolle spielte. Bei der Arbeit an diesem Entwurf gab es wiederholt Kontakte zum Stuttgarter Länderrat, und dabei erfolgte auch eine gewisse Koordination mit den entsprechenden Arbeiten in der USZone $^{16}$.

- Doch im November 1947 handelte auch in der französischen Zone die Militärregierung aus eigener Machtvollkommenheit und erließ zeitgleich mit dem Militärregierungsgesetz Nr. 59 der amerikanischen Zone die Verordnung Nr. 120, in der die Rückerstattung wiederauffindbaren Eigentums für das französisch besetzte Gebiet geregelt wurde ${ }^{17}$. Diese Verordnung war ohne deutsche Beteiligung zustandegekommen, dafür hatte die innerfranzösische Restitutionsgesetzgebung wichtige Impulse gegeben, die zumindest passagenweise wörtlich übernommen worden war ${ }^{18}$. Auch hier hatte die Verlagerung der Beratungen auf die Ebene des alliierten Kontrollrats jegliche deutsche Partizipation verhindert. Die französische Delegation hatte bei den Kontrollratsverhandlungen um ein gemeinsames Rückerstattungsgesetz insbesondere an den von amerikanischer Seite geforderten jüdischen Nachfolgeorganisationen für erbenloses Eigentum Anstoß genommen ${ }^{19}$. In ihrem eigenen zonalen Gesetz trug Frankreich nun diesen Bedenken Rechnung und ließ diese Werte in einen Fonds fließen, der zur Finanzierung der Entschädigung dienen sollte ${ }^{20}$. Erst 1951 änderte sich die französische Position, und auch in der französischen Zone wurden nun jüdische Nachfolgeorganisationen genehmigt $^{21}$. In mancher Hinsicht entsprach die Verordnung Nr. 120 mehr den deutschen Wünschen als die Rückerstattungsregelungen der anderen Zonen. Ein Beispiel dafür war die günstigere Stellung gutgläubiger Erwerber von jüdischem Eigentum in der VO $\mathrm{Nr} .120^{22}$. So wurde das Rückerstattungsgesetz der französischen Zone teilweise sogar zum Vorbild für deutsche Bestrebungen zur Änderung insbesondere des amerikanischen Militärregierungsgesetzes $\mathrm{Nr} .59^{23}$.

Im Juni 1948 erließ die französische Militärregierung schließlich die Verordnung No. 164, die die Länder der französischen Zone zur Ausarbeitung von Entschädigungsregelungen anwies und den Rahmen der gewünschten Leistungen absteckte ${ }^{24}$. Sie bestimmte zugleich, daß die Finanzierung nicht aus Haushaltsmitteln, sondern in erster Linie durch besondere Maßnahmen erfolgen sollte. Dazu gehörten insbesondere das bei der Rückerstattung anfallende erbenlose Vermögen sowie Erlöse aus dem Heimfall von Vermögenswerten nationalsozialistischer Organisationen und aus der Entnazifizie-

16 Vgl. Hudemann, Anfänge der Wiedergutmachung, S. 196-198, $207 \mathrm{f}$.

17 VO Nr. 120 über die Rückerstattung geraubter Vermögensobjekte, 10.11. 1947, in: Journal Officiel, Amtsblatt des französischen Oberkommandos in Deutschland, Nr. 119, 14.11. 1947, S. 1219-1222.

18 Vgl. Schwarz, Rückerstattung nach den Gesetzen der Alliierten Mächte, S. 292-294; Hudemann, Anfänge der Wiedergutmachung, S. $203 \mathrm{f}$.

19 Vgl. Drittes Kapitel, S. $119 \mathrm{f}$.

20 Artikel 9, VO Nr. 120.

21 Vgl. Schwarz, Rückerstattung nach den Gesetzen der Alliierten Mächte, S. 293.

22 Artikel 3, 6, VO Nr. 120.

23 Vgl. dazu Sechstes Kapitel, Abschnitt I. 1.

24 VO Nr. 164 über die Entschädigung der Opfer des Nazismus vom 29.6. 1948, in: Journal Officiel, Amtsblatt des französischen Oberkommandos in Deutschland, S. $1583 \mathrm{ff}$. Vgl. auch Féaux de la Croix, Vom Unrecht zur Entschädigung, S. $18 \mathrm{f}$. 
rung $^{25}$. Damit hielt man in der französischen Zone weiterhin an einer Linie fest, die in den anderen Westzonen bereits weitgehend aufgegeben worden war. Anfang 1950 folgten die Länder Baden, Rheinland-Pfalz und Württemberg-Hohenzollern dieser Aufforderung und erließen jeweils Gesetze über die Entschädigung der Opfer des Nationalsozialismus, die in gemeinsamen Beratungen entstanden waren und deren Struktur stark an das Entschädigungsgesetz der US-Zone angelehnt war ${ }^{26}$. An der Saar hatte es ein derartiges Entschädigungsgesetz sogar bereits 1948 gegeben, das somit das erste dieser Art im besetzten Deutschland darstellte ${ }^{27}$.

\section{Wer ist schuld an der Zersplitterung des Wiedergutmachungsrechts?}

Walter Schwarz und Ernst Féaux de la Croix schieben in ihren Darstellungen der französischen Politik den Schwarzen Peter dafür zu, daß es in der Besatzungszeit zu keiner überzonal koordinierten Politik im Bereich der Wiedergutmachung gekommen war ${ }^{28}$. Demgegenüber versucht Rainer Hudemann, der auch auf diesem Feld die Rehabilitierung der französischen Besatzungspolitik vom Vorwurf der Obstruktion anstrebt, diesen Makel von ihr zu nehmen. Zu diesem Zweck verweist er auf die Beteiligung deutscher Stellen aus der französischen Zone an informellen Kontakten mit den Sachverständigen aus anderen Zonen, was viel dazu beigetragen habe, daß sich in den Grundstrukturen einige wesentliche Gemeinsamkeiten herausbildeten ${ }^{29}$. Zudem verteidigt er auch die französische Haltung in den Kontrollratsverhandlungen, die er als durchaus konstruktiv bewertet. Daß die Franzosen schließlich nicht bereit waren, die amerikanische Regelung zu unterstützen, begründet Hudemann mit deren eigenständigem Demokratisierungskonzept für Deutschland ${ }^{30}$.

Tatsache ist, daß die amerikanische Militärregierung als einzige darum kämpfte, ihr Modell zumindest für die Westzonen als verbindlich durchzusetzen. Dies berechtigt aber gewiß nicht dazu, die fehlende Bereitschaft auf französischer und britischer Seite, diese Regelungen zu übernehmen, als Obstruktionspolitik zu qualifizieren. Die Untersuchung der alliierten Verhandlungen über Fragen der Wiedergutmachung im Kontrollrat hatte gezeigt, daß grundsätzliche gesellschaftspolitische Differenzen, aber auch innenpolitische Verpflichtungen eine alliierte Einigung auf diesem Gebiet verhinder$\operatorname{ten}^{31}$. Doch hat es aus heutiger Sicht auch eine positive Seite, daß keine alliierte Einigung über die Köpfe der Deutschen hinweg gelang: Wiedergutmachungsgesetze des Kontrollrats wären, so wie es auch den durch die Militärregierungen erlassenen Rückerstattungsgesetzen widerfuhr, stets mit dem Odium des alliierten Diktats behaftet geblieben. Demgegenüber sorgte die alliierte Nichteinigung zwar für aus der Verfolgten-

25 Artikel 10, VO Nr. 164.

26 Vgl. Hudemann, Anfänge der Wiedergutmachung, S. 213.

27 Amtsblatt der Verwaltungskommission des Saarlandes, 1948, S. 1122-1129. Vgl. auch Féaux de la Croix, Vom Unrecht zur Entschädigung, S. 30.

28 Vgl. Schwarz, Rückerstattung nach den Gesetzen der Alliierten Mächte, S. 293; Féaux de la Croix, Vom Unrecht zur Entschädigung, S. 36.

29 Vgl. Hudemann, Anfänge der Wiedergutmachung, S. $196 \mathrm{f}$.

30 Vgl. ebenda, S. 201.

31 Vgl. Drittes Kapitel, S. 118-121. Dort wo wie in Berlin alliierte Finigung unbedingt erforderlich war, war sie im übrigen auch möglich: Am 26. Juli 1949 erließen die drei Westmächte, die in der Alliierten Kommandantur für Berlin vertreten waren, ein gemeinsames Rückerstattungsgesetz für Westberlin, das weitgehend auf der Regelung in der britischen Zone beruhte. Vgl. Schwarz, Rückerstattung nach den Gesetzen der Alliierten Mächte, S.67. 
perspektive unerwünschte Verzögerungen auf dem Wege zu einer Wiedergutmachung, hielt aber wenigstens die Möglichkeit offen, daß diese Materie von deutscher Seite in eigener Verantwortung geregelt und so zumindest partiell auch zum Ausdruck eines Selbstreinigungsprozesses werden konnte.

Allerdings vermochte sich unter den Rahmenbedingungen der Zerstückelung in getrennte Besatzungszonen auch die deutsche Seite nicht über den mangelnden alliierten Konsens hinwegzusetzen. Dies zeigen die vergeblichen Versuche Philipp Auerbachs, eine überzonale Zusammenarbeit auf deutscher Ebene im Bereich der Verfolgtenbetreuung und Wiedergutmachung zuwege zu bringen. Bereits im Dezember 1946 hatte er in Tegernsee eine Interzonenkonferenz der staatlichen Wiedergutmachungsbeauftragten sowie der rassisch, religiös und politisch Verfolgten der drei westlichen Zonen organisiert. Dort wurde neben zahlreichen Beschlüssen zur Verbesserung der Lage der Verfolgten auch der Vorschlag Auerbachs zur Gründung eines vierzonalen Interzonensekretariats angenommen ${ }^{32}$. Doch hatte die amerikanische Militärregierung auf diese Initiative ablehnend reagiert: „four-zonal economic unity in Germany should be effected prior to the discussion of four-zonal unity problems“"33.

So kam es bis 1949 zu keiner gemeinsamen deutschen Politik im Bereich der Wiedergutmachung, wenngleich Entwürfe und Informationen auf interministerieller Ebene ausgetauscht wurden. Auch hatten seit 1948 - wiederum unter Auerbachs Ägide Tagungen der Wiedergutmachungsreferenten der drei westlichen Besatzungszonen stattgefunden, die zwar keinen regierungsamtlichen Charakter besaßen, aber gemeinsame Stellungnahmen zur Entwicklung der Wiedergutmachung erarbeiteten. Daraus ging 1949 die „Interministerielle Arbeitsgemeinschaft der Sachbearbeiter für Wiedergutmachungs- und Entschädigungsfragen für rassisch, religiös und politisch Verfolgte in der amerikanischen, britischen und französischen Zone" hervor, der Auerbach als Leiter vorstand. Doch über eine beratende Funktion gelangte auch dieses Gremium vor der Gründung der Bundesrepublik nicht hinaus.

Zusammenfassend läßt sich sagen, daß zwar in den Grundprinzipien trotz aller Widrigkeiten ein gewisses $\mathrm{Maß}$ an Übereinstimmung erreicht worden war. Vor allem im Bereich der Rückerstattung wiederauffindbaren Eigentums, den die Alliierten überwiegend in eigener Zuständigkeit geregelt hatten, hatte sich das amerikanische Modell weitgehend als Prototyp durchsetzen können. Aber besonders im Bereich der Entschädigung blieben zahlreiche Probleme bestehen. Die Rechtsungleichheit wirkte sich nicht zuletzt in unterschiedlichen Fristen und Zuständigkeiten aus, häufig zum Nachteil der Verfolgten. Zudem differierten die Ansprüche der Verfolgten je nach Zone oder Land zum Teil beträchtlich. Der schwerwiegendste Punkt war jedoch, daß in der britischen Zone eine allgemeine Entschädigungsgesetzgebung noch überhaupt fehlte. So bestanden also unter den einzelnen Ländern und Zonen erhebliche rechtliche Disparitäten, von denen der amerikanische Hohe Kommissar McCloy die Entfachung einer Dynamik zugunsten einer Vereinheitlichung in der Bundesrepublik auf dem Niveau des Entschädigungsgesetzes der US-Zone erwartete ${ }^{34}$.

32 Notizen von Herrn Staatskommissar Dr. Auerbach über das zu gründende Interzonensekretariat, 9. 12. 1946, im Protokoll der Interzonentagung in Tegernsee, 7.-9. 12. 1946, NL Hoegner, IfZ-Archiv, ED 120, Bd. 327.

33 G.H. Garde (AG/OMGUS) an Director/OMGB, IfZ-Archiv, MF 260, OMGUS-CAD 3/173-1/21.

34 Vgl. Drittes Kapitel, S. 147. 


\section{Veränderungen der innen- und außenpolitischen Rahmenbedingungen}

\section{Wiedergutmachung im Spannungsfeld zwischen Bund und Ländern}

Als Folge der Gründung der Bundesrepublik ergab sich ein Dualismus zwischen den Ländern als den bisherigen Trägern der Wiedergutmachungsanstrengungen und dem Bund. Zwar blieb die Durchführung der Wiedergutmachung zum größten Teil Ländersache, doch bestand bei der künftigen Gesetzgebung durch das Grundgesetz (Art.74, Nr.9) eine Konkurrenz zwischen Bund und Ländern. Zugleich intensivierten die Länder nun ihre Kontakte auch über die Zonengrenzen hinweg, woran vor allem Philipp Auerbach großen Anteil hatte, der die bereits früher aufgenommene inoffizielle Zusammenarbeit der Wiedergutmachungsreferenten der Länder ausbaute. Aus den von ihm initiierten Vorläufern in der Zeit vor Gründung der Bundesrepublik entstand das „Koordinierungsbüro der Interministeriellen Arbeitsgemeinschaft für Wiedergutmachungs- und Entschädigungsfragen in der Bundesrepublik Deutschland“, das Anfang 1951 schließlich in die „Konferenz der Obersten Wiedergutmachungsbehörden in der Bundesrepublik Deutschland“ umgebildet wurde.

Nach Auerbachs Verhaftung im März 1951 löste Otto Küster diesen als Leiter der Konferenz ab und verlegte die Geschäftsstelle von München nach Stuttgart ${ }^{35}$. Sowohl die Ambitionen Auerbachs wie auch Küsters waren zunächst vor allem darauf gerichtet, die Entschädigung auf Länderebene zu regeln und auszubauen. Diesem Zweck sollte ursprünglich auch der Ende 1951 gegründete Sonderausschuß für Wiedergutmachungsfragen des Bundesrates ${ }^{36}$ dienen, der bald die Konferenz als zentrales Organ der Länder an Bedeutung überflügelte. Im Oktober 1953 ging ohnehin die Koordinierungsaufgabe unter den Ländern auf regelmäßige Tagungen der Wiedergutmachungsreferenten der Länder über, zu denen auch Vertreter der zuständigen Bonner Ministerien hinzugezogen wurden ${ }^{37}$.

Auf Bundesebene bildeten sich entsprechende Strukturen erst mit einer gewissen Verzögerung aus. Der von Adenauer in einem Interview mit dem Herausgeber der Allgemeinen Wochenzeitung der Juden in Deutschland, Karl Marx, Ende 1949 vorgebrachte Gedanke, im Bundesinnenministerium ein Referat für jüdische Angelegenheiten einzurichten und einem deutschen Juden zu übertragen ${ }^{38}$, wurde nicht verwirklicht, nachdem der Zentralrat der Juden in Deutschland schließlich abgewinkt hatte ${ }^{39}$. Hoffnungen auf diesen Posten hatte sich auch Philipp Auerbach gemacht ${ }^{40}$. So wurden die einzelnen Bereiche der Wiedergutmachung auf verschiedene Bundesressorts verteilt: Das Bundesfinanzministerium wurde für die Entschädigung federführend, das Bundesinnenministerium für die Wiedergutmachung für den öffentlichen Dienst, das Bundes-

35 Protokolle des Koordinierungsbüros, BayMJ, 1091. Vgl. auch Féaux de la Croix, Vom Unrecht zur Entschädigung, S. $42 \mathrm{f}$. u. $60 \mathrm{f}$, der allerdings die Vorläufer in der Besatzungszeit übersah.

${ }^{36}$ Deutscher Bundestag, 74. Sitzung vom 7. 12. 1951, Stenographische Berichte, Bd. 4, S. 832.

${ }^{37}$ Vgl. Féaux de la Croix, Vom Unrecht zur Entschädigung, S. 62.

${ }^{38}$ Interview Karl Marx mit Konrad Adenauer, Allgemeine Wochenzeitung der Juden in Deutschland, 25. 11. 1949.

39 Direktorium des Zentralrates der Juden in Deutschland an Ritter v. Lex (Bundesinnenministerium), 16. 10. 1950, Handakten Auerbach im Besitz Hendryk Ingsters.

to Interview des Verfassers mit Hendryk Ingster am 27.7. 1987. Siehe auch Auerbach an Ringelmann, 26.11. 1949, Akten des bayerischen Finanzministeriums, Az. IV-N-402, Bd. VII-IX. 
justizministerium für Rückerstattung und Strafrechtspflege und das Bundesarbeitsministerium für Wiedergutmachung auf dem Gebiet der Sozialversicherung ${ }^{41}$. Im Bundestag wurden Wiedergutmachungsfragen zunächst vor allem im Aussschuß für Rechtswesen und Verfassungsrecht behandelt, erst 1955 wurde ein eigener Bundestagsausschuß für Wiedergutmachung gegründet. Aus dieser Situation ergab sich ein kompliziertes Ineinandergreifen von politischen Aktivitäten auf Länder- und Bundesebene.

\section{Alliierte Kontrolle der Wiedergutmachung in der Bundesrepublik?}

Auch nach der Gründung der Bundesrepublik blieben die Alliierten zunächst ein wichtiger Faktor in der Wiedergutmachungsfrage, wenngleich ihr Einfluß nun sukzessive zurückging. Der Alliierte Kontrollrat war im Sommer 1949 durch die Alliierte Hohe Kommission abgelöst worden. Deren Befugnisse waren in dem am 21. September 1949 in Kraft getretenen Besatzungsstatut niedergelegt, das - zwischendurch mehrfach geändert - bis zum 5. Mai 1955 gültig blieb. War die Bundesrepublik durch das Besatzungsstatut auch im Hinblick auf die Wiedergutmachung konkret gebunden?

Ernst Féaux de la Croix und Walter Schwarz widersprechen sich hierbei in ihren Darstellungen. Probleme ergeben sich dabei vor allem aus der Interpretation des Absatzes 2(b) des Besatzungsstatuts, der die "Restitutionen“ unter alliierten Vorbehalt stell$\mathrm{te}^{42}$. Féaux de la Croix vertritt die Auffassung, daß sich dieser Vorbehalt nur auf die äußeren Restitutionen bezog ${ }^{43}$, eine Auffassung, die in der ersten Zeit nach Gründung der Bundesrepublik bis in höchste deutsche politische Kreise herrschte ${ }^{44}$. Schwarz zufolge war damit hingegen auch die innere Restitution, d. h. also die Rückerstattung, gemeint ${ }^{45}$. Das Problem dabei ist, daß, wenn man so will, beide Recht haben, nämlich Féaux de la Croix im Hinblick auf die ursprüngliche Intention und Schwarz im Hinblick auf die spätere Auslegung durch die Alliierte Hohe Kommission. Um dies zu erklären, muß man zunächst einen Blick auf die Entstehung der betreffenden Abschnitte des Besatzungsstatuts werfen.

Bereits auf der Londoner Sechs-Mächte-Konferenz 1948 wurden die Grundzüge der Beziehungen zwischen den Besatzungsmächten und einer künftigen Bundesregierung festgelegt. Diese wurden den westdeutschen Ministerpräsidenten am 1. Juli 1948 im dritten der sogenannten „Frankfurter Dokumente“ mitgeteilt ${ }^{46}$. Unter den dort kurz skizzierten alliierten Vorbehaltsrechten befand sich aber keinerlei direkter Bezug auf die Ansprüche der Verfolgten des Nationalsozialismus, vielmehr zielten diese vorrangig auf die Beruhigung der französischen Seite angesichts der in London beschlossenen

41 Kurzprotokoll über die interministerielle Referentenbesprechung im Bundesjustizministerium am 16.5. 1950, BA, B 126/12523.

42 Besatzungsstatut, 12.5. 1949, in: Amtsblatt der Hohen Alliierten Kommission in Deutschland, Nr. 1, 23.9. 1949, S. 13-15.

43 Vgl. Féaux de la Croix, Vom Unrecht zur Entschädigung, S. 124 f.

44 Votum Oberregierungsrat Gumbels (Bundeskanzleramt), Adenauer vorzulegen, 20.12. 1949, BA, B 136/ 1124; Kurzprotokoll der 98. Sitzung des Bundestagsausschusses für Rechtswesen und Verfassungsrecht, 18.4. 1951, BA, B 126/12523.

${ }^{45}$ Vgl. Schwarz, Rückerstattung nach den Gesetzen der Alliierten Mächte, S. $82 \mathrm{f}$.

${ }^{46}$ Dokumente zur künftigen politischen Entwicklung Deutschlands ("Frankfurter Dokumente"), insbesondere Dokument Nr. 3 (Grundzüge eines Besatzungsstatuts), Frankfurt, 1.7. 1948, in: Der Parlamentarische Rat 1948-1949, Akten und Protokolle, Bd. 1: Vorgeschichte, bearb. v. Johannes Volker Wagner, Boppard am Rhein 1975, S. 33-36; Wolfgang Benz, Von der Besatzungsherrschaft zur Bundesrepublik. Stationen einer Staatsgründung 1946-1949, Frankfurt a.M. 1984, S. 159-162. 
Westeinbindung der drei westlichen Zonen Deutschlands. Auf der Grundlage dieses Dokuments und zusätzlicher, gleichfalls auf der Londoner Sechs-Mächte-Konferenz verabschiedeter Anweisungen beriet seit August ein Ausschuß der drei westlichen Militärregierungen über den endgültigen Inhalt eines Besatzungsstatuts ${ }^{47}$. Bereits Ende Oktober legte dieser einen ersten Entwurf vor. Unter den dort vorgesehenen alliierten Vorbehaltsrechten fand sich auch die Verpflichtung, „das Eigentum von Opfern der Nazi-Verfolgung zu schützen und zurückzuerstatten " ${ }^{48}$. Nach Auffassung der USDelegation sollte dies sowohl Deutsche wie auch Nicht-Deutsche einschließen, wogegen Briten und Franzosen zunächst nichts einzuwenden hatten ${ }^{49}$. Damit war also neben der äußeren auch die innere Restitution in diesem Entwurf verankert worden. Auffallend ist hier wiederum der Vorrang der Restitution vor der Entschädigung persönlicher Schäden, für die keine entsprechende Bestimmung vorgesehen wurde ${ }^{50}$. Im Dezember beendete der Ausschuß der Militärregierungen seine Arbeit und legte einen nochmals modifizierten Entwurf vor, in dem an dieser Bestimmung zugunsten der Rückerstattung für Opfer des Nationalsozialismus, wenn auch in veränderter Formulierung, festgehalten wurde ${ }^{51}$.

Doch änderte sich dies, als nun die Beratungen auf Regierungsebene fortgesetzt wurden. Auf der Eröffnungssitzung der neuen Gesprächsrunde im Londoner Foreign Office am 17. Januar 1949 fragten die französischen und britischen Delegationen nach, ob die US-Regierung nur ausländische Opfer oder auch deutsche Staatsangehörige, die aus rassischen, religiösen oder politischen Gründen verfolgt worden seien, schützen wolle. Selbst lehnten sie es ausdrücklich ab, deutsche Staatsbürger in diesem Zusammenhang zu berücksichtigen ${ }^{52}$. In der am 2. April 1949 in London beschlossenen Fassung des Besatzungsstatuts wurden deshalb die Rückerstattungsansprüche deutscher Staatsangehöriger nicht mehr in die alliierten Vorbehaltsrechte einbezogen. Nunmehr waren nur noch Vermögensinteressen ausländischer Staatsbürger berücksichtigt, und auch der potentielle Ausweitungen implizierende Begriff der Verfolgten des Nationalsozialismus war eliminiert worden ${ }^{53}$.

Daran änderten auch die abschließenden Beratungen auf der Washingtoner Außen-

${ }^{47}$ Einen sehr hilfreichen Überblick über Chronologie und Grundprobleme der alliierten Verhandlungen um das Besatzungsstatut gibt Wolfram Werner (Bearbeiter), In: Der Parlamentarische Rat 1948-1949, Bd. 4, Ausschuß für das Besatzungsstatut, Boppard am Rhein 1989, S. XIII-XVII.

48 Art. II, Abs. 2(f), Draft Joint Text of the Occupation Statute, Proposal by the Tripartite Committee on the Occupation Statute, 25. 10. 1948, in: Foreign Relations of the United States (FRUS), 1948, Bd. II: Germany and Austria, Washington, D.C., 1973, S.619.

${ }^{49}$ Robert Murphy an Secretary of State, 19.1. 1949, IfZ-Archiv, MA 1409/93, 740.00119/Control (Germany), 1-1949.

50 Max Isenbergh, ein Vertreter des American Jewish Committee, erhielt bei Gesprächen mit OMGUS-Angehörigen, vermutlich von Hans Simons, Ende 1948 die Auskunft, daß eine zunächst vorgesehene Bestimmung über alliierte Vorbehaltsrechte im Bereich der Entschädigung fallengelassen worden sei, nachdem in der USZone ein Entschädigungsgesetz in Vorbereitung sei. (Max Isenbergh an Foreign Affairs Department/AJC, 27. 12. 1948, YIVO-Archiv, RG 347, AJC, Records GEN-10, Box 282). Doch erscheint dieses Argument wenig schlüssig, denn dann hätte man ja analog auch auf eine Bestimmung zugunsten der Rückerstattung verzichten können.

51 Art. II, Abs. 2(f), Draft Joint Text of Occupation Statute, 17. 12. 1948, in: FRUS 1948 II, S.655: „To protect and restitute property belonging to non-German states or their nationals and property of victims of Nazi persecution “.

52 Julius C. Holmes (Leiter der US-Delegation in London) an Acting Secretary of State, 17.1. 1949, in: FRUS 1949, Bd. III: Council of Foreign Ministers; Germany and Austria, Washington 1974, S.9f.

53 Joint Text of the Occupation Statute Proclamation, 2.4. 1949, in: FRUS 1949 III, S. 65-73, insbesondere Art. II, Abs. 2(f), S. 66. 
ministerkonferenz vom 5. bis 8. April nichts mehr, wo der endgültige Text des Besatzungsstatuts festgelegt wurde ${ }^{54}$. Der alliierte Vorbehalt bezüglich der Restitutionen im Besatzungsstatut (Abs. (2b)) war somit eigentlich nur auf die äußere Restitution bezogen. Doch der amerikanische Hohe Kommissar faßte, wie sich dann zeigen sollte, sehr wohl auch die inneren Restitutionen unter diesen Begriff ${ }^{55}$. Zugleich leiteten die Amerikaner aus diesem Artikel auch Kontrollrechte für den Bereich der Entschädigung ab ${ }^{56}$. Überdies gab die alliierte Zuständigkeit für die DP's (Abs. (2d)) gleichfalls eine gewisse Handhabe zur Beeinflussung der Entschädigung. Besonders wichtig war, daß vor dem Inkrafttreten des Grundgesetzes erlassene alliierte Gesetze weiterhin unter Vorbehalt standen (Abs. 7), worunter auch die alliierten Rückerstattungsgesetze fielen ${ }^{57}$.

Doch trotz dieser Bestimmungen des Besatzungsstatuts war die alliierte Kontrolle der Wiedergutmachung in der Bundesrepublik in deren Anfangsjahren deutlich schwächer als vor der Weststaatsgründung. Dies galt vor allem für den Ausbau der bisherigen Regelungen. In dieser Beziehung konnte alliierter Einfluß oder gar Druck fortan nur als Wirkung der allgemeinen politischen „bargaining power“ wirksam werden, jedoch nicht aufgrund eines konkreten Auftrags des Besatzungsstatuts. Rückblickend erklärte dazu der amerikanische Hohe Kommissar John J. McCloy, daß die Alliierten keine förmlichen gesetzgeberischen Rechte im Bereich der Wiedergutmachung besessen hätten: „We could exert pressure, we could persuade, but we couldn't dictate. " 58

\section{Organisation der Verfolgteninteressen: Fragmentierung und Zusammenschluß}

Bedeutsame Veränderungen ergaben sich aber auch auf dem Feld der Interessenvertretung durch die Verfolgten. Bei diesen lassen sich zwei Hauptgruppen unterscheiden: Einmal die jüdischen Verfolgten, auf der anderen Seite alle übrigen Verfolgten, von denen vor allem die nichtjüdischen deutschen Verfolgten wichtig waren. (Daneben spielten ausländische nichtjüdische Verbände eine eher marginale Rolle.) Dabei zeigen sich organisations- und daraus resultierend wirkungsgeschichtlich zwei ganz unterschiedliche Entwicklungen.

Martin Hirsch, SPD-Bundestagsabgeordneter, Verfassungsrichter und langjähriger Vorsitzender des Bundestags-Wiedergutmachungsausschusses, erklärte bei Gelegenheit einer Tagung Mitte der achtziger Jahre über die unterschiedlichen Chancen der Durchsetzung von Wiedergutmachungsinteressen: „Aber generelle Schwierigkeiten hatten am meisten die politisch Verfolgten und die Zigeuner, die weitgehend zunächst vergessen oder falsch behandelt worden sind. Die politisch Verfolgten sind z.T. selber daran schuld, weil sie sich sehr schnell zersplittert haben. ${ }^{499}$ Tatsächlich hatte Anfang der

54 Occupation Statute Defining the Powers to be Retained by the Occupation Authorities, Washington, 8.4. 1949, in: FRUS 1949 III, S. 179-181.

55 Vgl. Viertes Kapitel, Abschnitt II. 2.

${ }^{56}$ Memorandum von Frank J. Miller (HICOG/Property Group) vom 12.8. 1949, IfZ-Archiv, MF 260, OMGUS-CO 11/44-2/27.

57 Besatzungsstatut, 12.5. 1949, in: Amtsblatt der Hohen Alliierten Kommission in Deutschland, Nr. 1, 23. 9. 1949, S. 13-15.

58 Interview mit John J. McCloy am 23. 2. 1972, Jacob Blaustein Oral History Project, William E. Wiener Oral History Library of the American Jewish Committee.

59 Martin Hirsch, Folgen der Verfolgung. Schädigung - Wiedergutmachung - Rehabilitierung, in: Die Bundesrepublik Deutschland und die Opfer des Nationalsozialismus, Protokolldienst 14/84, Bad Boll 1984, S. 19-32. 
fünfziger Jahre eine starke Fragmentierung der deutschen Verfolgtenverbände stattgefunden, deren Vorboten freilich schon seit etwa $1948 \mathrm{zu}$ erkennen gewesen waren.

Es war bereits die Rede davon, daß sich 1946 in allen vier Zonen als eine einheitliche Organisation der rassisch, religiös und politisch Verfolgten die Vereinigung der Verfolgten des Naziregimes (VVN) gebildet hatte, in der prinzipiell alle deutschen Opfer des Nationalsozialismus vertreten waren. Noch im April 1948 pries Eugen Kogon, der zu dieser Zeit selbst dem Vorstand der hessischen VVN angehörte, in den Frankfurter Heften diese Organisation "mit ihren dreihunderttausend Mitgliedern in Deutschland“ als das „einzige große politische Forum, wo Deutsche der verschiedensten Herkunft, Konfession und Parteizugehörigkeit aufgrund einer gemeinsam durchkämpften und durchlittenen Vergangenheit noch zusammenwirken." Die VVN genieße zwar „beim deutschen Volk kein sonderlich gutes Ansehen“, da ihre Mitglieder immer noch mit dem Odium ihrer einstigen Verfolgung behaftet seien. Doch sei sie „kein Verband der Einflußlosen: Dutzende von deutschen Ministern, Staatssekretären und Parteiführern in allen Besatzungszonen, Hunderte von maßgebenden Männern und Frauen des öffentlichen Lebens gehören ihr an ${ }^{“ 60}$. Doch genau ein Jahr später trug Kogon an selber Stelle seine früheren Hoffnungen auf eine tragende politische Rolle des europäischen Widerstandes zu Grabe ${ }^{61}$. Und enttäuscht revidierte er seine euphorischen Bemerkungen über die Rolle der VVN in der deutschen Gesellschaft: „Legen wir's zum übrigen. “ 62

Die Gemeinsamkeit der erlittenen Verfolgungen konnte die politischen Differenzen innerhalb der VVN nicht überbrücken, vor allem nachdem sich diese immer stärker im Ost-West-Konflikt engagierte. Die SPD, die unter Kurt Schumacher einen strikt antikommunistischen Kurs vertrat, distanzierte sich zuerst von der VVN, in der Kommunisten eine zunehmend stärkere Rolle spielten. Der Unvereinbarkeitsbeschluß des SPDParteivorstands vom Mai 1948, der die gleichzeitige Zugehörigkeit bei SPD und VVN untersagte, stellte die Fronten endgültig klar, wenngleich sich dies unter den Parteimitgliedern erst mit einiger Verzögerung durchsetzte. Zugleich wurden eine Zentralstelle für politisch verfolgte Sozialdemokraten, die die Mitwirkung an der Fortentwicklung der Wiedergutmachung zur Aufgabe hatte, sowie die mit ihr verbundene „Arbeitsgemeinschaft verfolgter Sozialdemokraten " (AvS) gegründet ${ }^{63}$.

Die Entwicklung der VVN zur kommunistischen Restorganisation verlief somit als ein sich wechselseitig verstärkender Prozeß: Auf die Vergrößerung des kommunistischen Einflusses reagierten die anderen politischen Gruppen mit der Aufkündigung der Zusammenarbeit, wodurch der kommunistische Charakter der VVN weiter zunahm. Am 4. Februar 1950 schließlich wurde in Düsseldorf von ehemaligen VVN-Mitgliedern als gezielt antikommunistische Gegengründung zur VVN der Bund der Verfolgten des Naziregimes (BVN) gegründet ${ }^{64}$. Der erste Vorsitzende des BVN, der Journalist und CDU-Politiker Peter Lütsches, hatte bereits im Vorfeld der Gründung Kontakt mit der

60 Eugen Kogon, Politik der Versöhnung, in: Frankfurter Hefte, 3. Jg., H. 4, April 1948, S. 317-324, hier: S. 321.

${ }^{61}$ Ders., Der politische Untergang des europäischen Widerstandes, in: Frankfurter Hefte, 4. Jg., H. 5, Mai 1949, S. 405-413, hier: S. 405.

62 Ebenda, S. 410 f.

${ }^{63}$ Jahrbuch der Sozialdemokratischen Partei Deutschlands 1948/49, hrsg. v. Vorstand der SPD, Hannover 1949, S. 130. Vgl. auch Susanne Miller, Die Behandlung des Widerstands gegen den Nationalsozialismus in der SPD nach 1945, in: Büttner (Hrsg.), Das Unrechtsregime, Bd. 2, S. $417 \mathrm{f}$.

64 Vgl. Widerstand. Gestern und Heute, hrsg. vom Bund der Verfolgten des Naziregimes (BVN), o.O. 1950, S. 2 ff.; 1 Jahr BVN, hrsg. v. Bundessekretariat des Bundes der Verfolgten des Naziregimes, Düsseldorf 1950. 
Bundesregierung hergestellt, um dort Unterstützung für die geplante Spaltung der VVN zu gewinnen. Adenauer begrüßte diese Initiative nachdrücklich ${ }^{65}$, und bald darauf trat er von der VVN, der er selbst angehört hatte, zum BVN über ${ }^{66}$.

Die damit entstandenen Hauptgruppierungen der politisch Verfolgten VVN, BVN und AvS zogen nun auch in Wiedergutmachungsangelegenheiten keineswegs an einem gemeinsamen Strang. Insbesondere zwischen VVN und BVN herschte ein ständiger Schlagabtausch. Doch gelang dem BVN nie der zahlenmäßig große Durchbruch, während andererseits die VVN als einstmals bedeutendste deutsche Verfolgtenorganisation immer weiter marginalisiert wurde. Sie richtete sich zunehmend stärker nach einem kommunistischen Antifaschismuskonzept aus und stellte sich politisch scharf gegen Adenauers Westintegrationspolitik ${ }^{67}$. Das führte bereits im September 1950 zum Beschluß des Bundeskabinetts, die Zugehörigkeit zur VVN künftig mit Berufsverbot im öffentlichen Dienst zu ahnden ${ }^{68}$. Die Bundesregierung empfahl den Landesregierungen, sofort entsprechende Maßnahmen zu ergreifen ${ }^{69}$, was auch insofern Folgen für die Durchführung der Wiedergutmachung besaß, als eine ganze Reihe von Mitarbeitern der Entschädigungsbehörden der VVN angehörte. Am 26. Juli beschloß das Bundeskabinett schließlich das Verbot des Rates der Vereinigung der Verfolgten des Naziregimes, d.h. der Dachorganisation der $\mathrm{VVN}^{70}$.

Weitere deutsche nichtjüdische Verbände blieben gleichfalls ohne große Bedeutung. Ein Anfang der fünfziger Jahre gegründeter „Zentralverband der Sterilisierten und Gesundheitsgeschädigten im Bundesgebiet e.V." versuchte vergeblich prominente Politiker zu einer Schirmherrschaft über ihren Verband zu gewinnen. Aber sowohl Bundespräsident Theodor Heuss als auch der bayerische Ministerpräsident Ehard lehnten dieses Ansinnen $\mathrm{ab}^{71}$. Die Zigeuner hingegen, um ein anderes Beispiel zu nennen, waren in dieser Zeit von einer Organisation ihrer Interessen noch weit entfernt; erst 1979 trat hier durch die Gründung des „Zentralrats der Sinti und Roma“ eine Änderung ein. So kann man konstatieren, daß etwa seit Beginn der fünfziger Jahre keine einheitliche Interessenvertretung der deutschen Verfolgten mehr existierte, was entscheidend zu ihrer weitgehenden Einflußlosigkeit im Bereich der Wiedergutmachung beitrug. Die Ursachen für diese Entwicklung liegen überwiegend in der mangelnden Homogenität der Interessen dieser Gruppe, oder anders gesagt: das Verfolgungserlebnis war von einem primären zu einem sekundären Faktor bei der gesellschaftlichen und politischen Orientierung der ehemaligen deutschen Verfolgten geworden.

65 41. Kabinettssitzung am 3.2. 1950, in: Die Kabinettsprotokolle der Bundesregierung, hrsg. f. d. Bundesarchiv v. Hans Booms, Bd. 2: 1950, bearbeitet v. Ulrich Enders u. Konrad Reiser, Boppard a. Rh. 1984, S. 184.

66 Adenauer an Peter Lütsches, 8.5. 1950, Adenauer. Briefe, Rhöndorfer Ausgabe, hrsg. v. Rudolf Morsey u. Hans-Peter Schwarz, Bd. 3: 1949-1951, bearb. v. Hans Peter Mensing, Berlin 1985, S. 207.

${ }^{67}$ Nach dem Zusammenbruch der SED-Herrschaft in der DDR Ende 1989 mußte die mittlerweile zur VVNBdA (Bund der Antifaschisten) umgeformte VVN ihre Arbeit weitgehend einschränken, da sie einen Großteil ihrer finanziellen Mittel von dort erhalten hatte.

68 97. Kabinettssitzung am 19. September 1950, in: Kabinettsprotokolle der Bundesregierung, Bd. 2, S. $702 \mathrm{f}$.

69 Beschluß der Bundesregierung, gez. Adenauer, 19. 9. 1950, HessHStA, Abt. 502, Nr. 2007. Als Beispiel für daraus resultierende Maßnahmen siehe etwa die „Richtlinien für die Entlassung von Staatsbediensteten wegen politischer Betätigung gegen die demokratische Grundordnung “, erlassen vom hessischen Minister des Innern am 19. 10. 1950, in: Staats-Anzeiger für das Land Hessen, Nr. 42, 21.10. 1950, S. 425.

70 164. Kabinettssitzung am 26.7. 1951, in: Kabinettsprotokolle der Bundesregierung, Bd. 2, S. $565 \mathrm{f}$.

71 Siehe dazu Der Notschrei. (Untertitel: Kampf- und Aufklärungsorgan der durch Naziterror Verstümmelten, Gesundheitsgeschädigten und Euthanasiehinterbliebenen), Jg. 1951, Nr. 3, 24. 12. 1951; bayerischer Ministerrat, 22.5. 1951, IfZ-Archiv, NL Hoegner, ED 120, Bd. 367. 
Ging also der Weg auf Seiten der deutschen, nichtjüdischen Verfolgten hin zu einer Zersplitterung, nahm die Entwicklung auf jüdischer Seite gerade den umgekehrten Verlauf. Zum einen hatte die 1948 erfolgte Gründung des Staates Israel, der sich als jüdische Gesamtvertretung betrachtete, große Bedeutung für die künftige Formulierung und Durchsetzung von Wiedergutmachungsansprüchen gegen Deutschland. Daneben entfaltete aber vor allem die im Oktober 1951 gegründete "Jewish Conference on Material Claims against Germany“, kurz Claims Conference, eine beträchtliche Wirkung auf diesem Gebiet. Martin Hirsch, der als langjähriger Vorsitzender des Bundestags-Wiedergutmachungsausschusses den Einfluß der Claims Conference kennengelernt hatte, erklärte einmal, daß diese „letztenendes eine Gründung von Konrad Adenauer war, nicht der Juden selber" 72 . Auf den ersten Blick erscheint dies einleuchtend, erfolgte doch die Gründung dieses Zusammenschlusses von 22 jüdischen Organisationen unmittelbar auf Adenauers Erklärung vor dem Bundestag am 27. September 1951, in der er unter anderem die Bereitschaft zu Verhandlungen mit dem Staat Israel und Vertretern des Judentums erklärt hatte ${ }^{73}$. Der Bundeskanzler wünschte aus praktischen Gründen eine einheitliche jüdische Vertretung als Gesprächspartner. Doch reichen die Anfänge einer Kooperation der jüdischen Organisationen bereits wesentlich weiter zurück. Eine intensive Zusammenarbeit auf dem Gebiet der Wiedergutmachung hatte es ja bereits seit 1945 gegeben. Insbesondere das gemeinsame Komitee der Jewish Agency for Palestine, des American Jewish Joint Distribution Committee, des World Jewish Congress und des American Jewish Committee hatte auf dem Gebiet der Rückerstattungs- und Entschädigungsgesetzgebung in der amerikanischen Besatzungszone beachtliche Erfolge verbuchen können. Dieses Komitee arbeitete auch 1950/51 weiter daran, die Durchführung dieser Gesetze in der Bundesrepublik zu sichern.

Israelische Vorstöße, die darauf abzielten, die Frage der jüdischen Kollektivansprüche wieder auf den Tisch zu bringen ${ }^{74}$, führten dazu, daß Nahum Goldmann Anfang Februar 1951 bei einer Besprechung dieses Komitees in New York vorschlug, daß es sich zum Zwecke von Verhandlungen mit Bonn erweitern solle. Er gedachte ihm dabei eine Mittlerrolle zu, für den Fall, daß Israel aus politisch-psychologischen Gründen nicht in direkte Verhandlungen mit der Bundesrepublik eintreten könne ${ }^{75}$. Eine große Rolle bei derartigen Überlegungen spielte aber auch, daß der Alleinvertretungsanspruch jüdischer Interessen durch Israel auf Widerstand eines Teils der jüdischen Organisationen stieß. Vor allem das American Jewish Committee, das eine Schlüsselrolle bei den Beziehungen zur amerikanischen Regierung einnahm, war nicht bereit, die Interessen der Diaspora-Juden völlig denen Israels unterzuordnen ${ }^{76}$.

Die Regierungserklärung Adenauers vor dem Bundestag am 27. September 1951 war somit nur das Signal, nicht aber der Anlaß zur Gründung der Claims Conference. Nahum Goldmann übernahm namens des jüdischen Weltkongresses die Initiative und lud am 25. Oktober 22 jüdische Organisationen aus aller Welt nach New York ein. Dies war die Geburtsstunde der Claims Conference, deren erster und langjähriger Präsident

72 Hirsch, Folgen der Verfolgung, S. 29.

${ }_{74}$ Deutscher Bundestag, 165. Sitzung vom 27.9. 1951, Stenographische Berichte, Bd. 9, S.6697f.

74 Vgl. dazu Sechstes Kapitel, S. 257.

75 Notes on Meeting No. 51-2 of the Four Organizations, 7.2. 1951, YIVO-Archiv, RG 347, AJC, Records GEN-10, Box 291.

76 Siehe dazu Simon Segal an John Slawson, „Meeting April 26th on Israeli Reparations Claim“, 8.5. 1951, YIVO-Archiv, RG 347, AJC, Records GEN-10, Box 282. 
Goldmann wurde. Einem solchen Zusammenschluß war von israelischer Seite ursprünglich vornehmlich die Rolle eines Akklamationsorgans zugunsten der eigenen Forderungen zugedacht worden. Tatsächlich entwickelte sich diese aber zu einem Gegengewicht zu Israel ${ }^{77}$.

Doch nicht nur zwischen dem Staat Israel und den Diaspora-Juden existierten solche Spannungen. Innerjüdische Schwierigkeiten von großer Relevanz für die Frage der Wiedergutmachung bestanden auch insbesondere im Verhältnis zu den Juden in Deutschland. Wiederholt gab es Schwierigkeiten, weil sich letztere von ihren Glaubensbrüdern benachteiligt fühlten. Auf der 2. Plenarversammlung des World Jewish Congress 1948 in Montreux hatte sich dieser noch deutlich gegen das Bestehen neuer jüdischer Gemeinden in Deutschland gewandt ${ }^{78}$, und ein Rest dieser Vorbehalte lag auch nach ihrer offiziellen Rehabilitierung 1950 noch in der Luft. Seit Juli dieses Jahres bestand mit dem Zentralrat der Juden in Deutschland eine gemeinsame Vertretung der jüdischen Interessen in der Bundesrepublik. Ausschlaggebend für diese Gründung war, wie ihr langjähriger Generalsekretär Hendrik George van Dam später erklärte, „zwei-

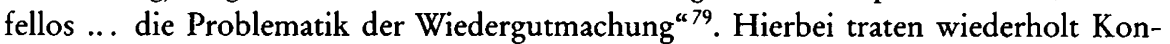
flikte mit der Claims Conference auf, weshalb der Zentralrat Anfang 1953 sogar kurz vor dem Austritt aus dieser stand, um seine Wiedergutmachungsinteressen in eigener Regie zu verfolgen ${ }^{80}$.

Trotz dieser und anderer heftiger innerer Konflikte zeigte sich die Claims Conference nach außen hin stets geschlossen. Eine Folge ihres Auftretens war dabei aber auch, daß sich die Tendenz, wonach jüdische Forderungen separat von denen aller anderen Opfer des Nationalsozialismus verfolgt wurden, weiter verfestigte. Dies ging soweit, daß die Claims Conference sogar ablehnte, die Forderungen von Nicht-Glaubensjuden mitzuvertreten, obwohl die Nationalsozialisten in dieser Hinsicht keinen Unterschied gemacht hatten ${ }^{81}$. Vereinzelt gab es Versuche, gegen diese Abschottung anzugehen. Bruno Weil, der Präsident der Axis Victims League, der schon 1942 vergeblich versucht hatte, zu einer Zusammenarbeit in Wiedergutmachungsfragen mit den jüdischen Organisationen zu kommen, schrieb am 24. Oktober, einen Tag vor Gründung der Claims Conference, an Frederick Goldschmidt von der URO in London: „Vergessen Sie bitte bei der ganzen Sache nicht, daß es sich nicht nur um jüdische Dinge handelt ... Wenn Dr. Adenauer aus politischen Gründen sich an Israel und die jüdischen Organisationen gewandt hat, so weiß doch jederman, daß von der israelischen Reparationsforderung abgesehen, alle anderen Fragen nur auf einer alle Rassen, Nationen und Religionen (die verfolgt worden sind) gleichermaßen umfassenden Basis geregelt werden können. Das Gegenteil würde bedeuten ... daß die nationalistischen und rassischen Grundsätze

${ }_{77}$ Vgl. Ronald W. Zweig, German Reparations and the Jewish World. A History of the Claims Conference, Boulder und London 1987, S. $52 \mathrm{ff}$.

${ }^{78} \mathrm{Vgl}$. Kurt R. Grossmann, Die jüdischen Auslandsorganisationen und ihre Arbeit in Deutschland, in: Die Juden in Deutschland. 1951/52 - 5712. 1958/59 - 5719. Ein Almanach, hrsg. v. Heinz Ganther, Hamburg 1959, S. 158-161.

${ }^{79} \mathrm{Vgl}$. Hendrik George van Dam, Die Juden in Deutschand nach 1945, in: Judentum. Schicksal, Wesen und Gegenwart, hrsg. v. Franz Böhm und Walter Dirks, Bd. II, Wiesbaden 1965, S. 888-916, hier, S. 900. Siehe dazu auch Summarisches Protokoll der Sitzung des Zentralrates am 7.1. 1951 in Hamburg, LBI-Archiv, Council of Jews from Germany, Folder 24.

${ }^{80}$ Bericht von Benjamin B. Ferencz über ein Treffen zwischen dem Zentralrat, der URO, dem JTC, dem AJDC und der JRSO in Bad Godesberg am 8. 2. 1953, LBI-Archiv, Council of Jews from Germany, Folder 20.

${ }^{81}$ Vgl. etwa Benjamin B. Ferencz, Lohn des Grauens. Die verweigerte Entschädigung für jüdische Zwangsarbeiter. Ein Kapitel deutscher Nachkriegsgeschichte, Frankfurt a.M. usw. 1981, S. 74. 
Hitlers noch nach seinem Tode anerkannt werden würden. " ${ }^{82}$ Nach Beginn der Verhandlungen der Claims Conference mit der deutschen Delegation in Wassenaar reichten Bruno Weil und Fritz Moses namens der Axis Victims League sowie weitere in den USA angesiedelte Verfolgtenverbände ${ }^{83}$ vergeblich eine Eingabe an die jüdischen und deutschen Delegationen ein, in der eine internationale und interkonfessionelle Konferenz gefordert wurde ${ }^{84}$.

So standen einem starken, geeinten Block jüdischer Wiedergutmachungsinteressen weiterhin zahlreiche andere Organisationen gegenüber, die kein entsprechendes Gewicht in die Waagschale werfen konnten. Die Claims Conference entwickelte sich dabei zu der mit Abstand einflußreichsten Verfolgtenlobby. Ihre Erfolge wären wohl nicht denkbar gewesen, wenn nicht immer noch Restbestände der Vorstellung über die wirtschaftliche und politische Macht des "Weltjudentums“ in deutschen Köpfen herumgespukt hätten ${ }^{85}$. Daran knüpften die jüdischen Organisationen mitunter auch gezielt an realere Instrumente, durch die sie diesen nützlichen Mythos hätten ersetzen können, standen ihnen seit der Gründung der Bundesrepublik kaum mehr zur Verfügung.

\section{Wandlungen der gesellschaftlichen Partizipation}

\section{Die Parlamentarisierung der Wiedergutmachung und die Rolle der Parteien}

Erhebliche Bedeutung hatte aber auch, daß die Wiedergutmachung seit der Gründung der Bundesrepublik nicht mehr länger weitgehend hinter verschlossenen Türen verhandelt wurde. Vor allem auch die US-Militärregierung hatte in der Zeit bis 1949 wiederholt zu verhindern gewußt, daß die Entschädigung und insbesondere die Rückerstattung Gegenstand deutscher parlamentarischer Beratungen wurden. Da sich dies nun änderte, wurden die Parlamente verstärkt zu Ansprechpartnern von „Wiedergutmachungs-Lobbyisten “. Dazu gehörten zum einen die Verfolgtenorganisationen, aber auch eher philanthropisch gestimmte Gruppen, wie etwa die von Erich Lüth und Rudolf Küstermaier im August 1951 gestartete Initiative „Friede mit Israel“ ${ }^{\alpha 6}$. Umgekehrt hatten sich aber auch beispielsweise die Rückerstattungsbetroffenen in lautstark auftretenden Vereinigungen organisiert und traten massiv an Parteien und Parlamente heran.

Das Interesse der im Bundestag vertretenen Parteien an der Wiedergutmachung war dabei sehr unterschiedlich ausgeprägt. Für die CDU besaß die Frage der Wiedergutmachung weder vor noch in den ersten Jahren nach Gründung der Bundesrepublik besondere Priorität. Ihre Aufmerksamkeit galt von Anfang an weniger den Verfolgten des Nationalsozialismus im besonderen als den zahlreichen Opfern des Krieges im allgemeinen. Die Leitsätze der CDU im Rheinland und Westfalen vom September 1945

${ }^{82}$ Weil an Frederick Goldschmidt, 24. 10. 1951, LBI-Archiv, Council of Jews from Germany, Folder 17.

83 Die K.Z. American Association of Former Inmates of Concentration Camps und die American Association of Former European Jurists.

${ }^{84}$ Bruno Weil, Adolf Hamburger usw. an die US-Botschaft in Den Haag, 23. 3. 1952, LBI-Archiv, Council of Jews from Germany, Folder 17.

85 Vgl. dazu auch Michael Wolffsohn, Globalentschädigung für Israel und die Juden? Adenauer und die Opposition in der Bundesregierung, in: Wiedergutmachung in der Bundesrepublik Deutschland, hrsg. v. Ludolf Herbst u. Constantin Goschler, München 1989, S. 189.

${ }^{86}$ Vgl. Erich Lüth, Die Friedensbitte an Israel 1951. Eine Hamburger Initiative, Hamburg 1976. 
forderten etwa gleichermaßen eine „besondere Fürsorge“ für „Opfer des nationalsozialistischen Regimes und des Krieges" ${ }^{47}$ und betonten damit die Gleichstellung dieser beiden Geschädigtenkreise. Überdies wurde der Begriff der nationalsozialistischen Verfolgung zum Teil recht eng gefaßt: So hieß es über diese Gruppe in einem vorläufigen Entwurf für ein Programm der CDU, das im Juni 1945 in Köln entstand: „In Ehrfurcht neigen wir uns vor den Blutzeugen des christlichen Glaubens und der bürgerlichen Freiheit, die dem Nationalsozialismus zum Opfer fielen. ${ }^{\text {" } 88}$ Erhebliche Teile der Opfer des NS-Regimes waren mit dieser Charakterisierung sicherlich nur unvollkommen erfaßt.

Eine herausragende Rolle in der Frage der Wiedergutmachung in den Reihen der CDU spielte unzweifelhaft Konrad Adenauer, vor allem in seiner Amtszeit als Bundeskanzler ${ }^{89}$. Dabei konzentrierte sich Adenauers persönliches Engagement auf den speziellen Aspekt der Wiedergutmachung für die Juden. Jedoch erscheinen die Vorgänge um die Judenverfolgung im Dritten Reich in den Worten Adenauers häufig seltsam unwirklich, wie durch eine dicke Nebelwand hindurch gesehen. Als Karl Marx, der Herausgeber des Jüdischen Gemeindeblatts für die britische Zone, im Frühjahr 1947 Adenauer um einen Beitrag für seine Zeitschrift bat, sandte dieser ihm die Zeilen: „Den deutschen Juden ist unter dem Nationalsozialismus bitterstes Unrecht geschehen ... Ich habe soviel ausgezeichnete jüdische Männer und Frauen in Deutschland kennengelernt - z.T. mußten sie emigrieren -, daß ich mich freuen würde, wenn sie möglichst bald nach Deutschland zurückkehren würden." Zugleich sprach sich Adenauer dort auch für Genugtuung und Hilfe nach Kräften für die jüdischen Gemeinden aus ${ }^{90}$.

In seiner ersten Regierungserklärung vor dem Bundestag am 21. September 1949 fand Adenauer zwar von den Flüchtlingen und Vertriebenen über die Opfer des Bombenkriegs für alle möglichen Geschädigtengruppen Worte, nicht aber für die Verfolgten des Nationalsozialismus ${ }^{91}$. Die heftige Kritik an dieser Unterlassung bewegte ihn bald darauf, Karl Marx, der mittlerweile Herausgeber der Allgemeinen Jüdischen Wochenzeitung für Deutschland war, ein Interview zu geben und dort das Versäumte nachzuholen. In diesem am 25. November 1949 veröffentlichten Gespräch erklärte der Kanzler erstmals die Absicht der Bundesregierung, die Verbrechen an den Juden wiedergutzumachen. Als ein erstes unmittelbares Zeichen, so Adenauer, wolle die Bundesregierung "dem Staat Israel Waren zum Wiederaufbau im Werte von 10 Millionen DM zur Verfügung stellen" ${ }^{\text {"2 }}$. Doch beklagte sich Marx ein Jahr später bitter bei Bundesjustizminister Dehler, daß aus „all den Zusagen, die Hr. Dr. Adenauer gemacht hat und aus all den Versprechungen, die er darüber hinaus in der Unterhaltung gegeben hat," nichts

87 "Leitsätze der Christlich Demokratischen Partei in Rheinland und Westfalen September 1945, in: Konrad Adenauer und die CDU der britischen Besatzungszone 1946-1949. Dokumente zur Gründungsgeschichte der CDU Deutschlands, hrsg. v. d. Konrad-Adenauer-Stiftung, Bonn 1975, S. 112.

88 "Ein Ruf zur Sammlung des Deutschen Volkes. Vorläufiger Entwurf zu einem Programm der Christlichen Demokraten Deutschlands, vorgelegt von den Christlichen Demokraten Kölns im Juni 1945“, in: ebenda, S. 106.

89 Vgl. hierzu auch Hans-Peter Schwarz, Adenauer. Der Aufstieg: 1876-1952, Stuttgart 1986, S. $897 \mathrm{ff}$.

90 Konrad Adenauer an die Synagogengemeinde Köln: Artikel für das „Jüdische Gemeindeblatt“, 25. 4. 1947, in: Adenauer. Briefe, Bd. 1, Rhöndorfer Ausgabe, hrsg. v. Rudolf Morsey u. Hans-Peter Schwarz, bearb.v. Hans Peter Mensing, Berlin 1983, S.473f.

91 Deutscher Bundestag, 6. Sitzung v. 21.9. 1949, Stenographische Berichte, Bd. 1, S. 36.

92 Konrad Adenauer, Interview mit Karl Marx am 11.11. 1949, in: Allgemeine Wochenzeitung der Juden in Deutschland, 25.11. 1949. 
geworden sei ${ }^{93}$. Aus dieser Beschwerde resultierte immerhin, daß die Bundesregierung über Dehler das Gespräch mit Marx suchte, der dabei auch israelische Interessen vertrat $^{94}$. Dies trug wesentlich dazu bei, daß Adenauer schließlich am 27. September 1951 in einer feierlichen Regierungserklärung vor dem Bundestag die Bereitschaft der Bundesregierung, mit Vertretern des Judentums und des Staates Israel über die Lösung des materiellen Wiedergutmachungsproblems zu verhandeln, erklärte ${ }^{95}$. Künftig zeigte er sich auch bereit, erhebliche Widerstände seiner Koalitionspartner und auch aus seiner eigenen Partei zu überwinden, um zu diesem Ziel zu gelangen. Doch ist es nicht möglich, pars pro toto zu nehmen und Adenauers Engagement für ein Abkommen mit Israel und der Claims Conference mit seinem Einsatz für die Wiedergutmachung für Opfer des Nationalsozialismus insgesamt gleichzusetzen. Abgesehen von diesem - wiewohl sehr wichtigen - Spezialfall nahm er kaum persönlichen Anteil an dieser Materie.

Bei einem Blick auf Adenauers Koalitionspartner erweist sich, daß hier die Bedeutung des Themas Wiedergutmachung eher noch geringer geschätzt wurde. Seitens der CSU exponierte sich auf diesem Gebiet besonders Fritz Schäffer, der im ersten Bundeskabinett als Finanzminister amtierte. Dabei trat er in erster Linie durch seinen hartnäkkigen Widerstand gegen ein Abkommen mit Israel und der Claims Conference sowie gegen die Regelung der Wiedergutmachung durch den Bund hervor ${ }^{96}$. Doch ähnlich wie bei Adenauer, dessen Haltung nicht allein durch Parteipolitik, sondern auch durch die Staatsräson beeinflußt wurde, ist bei Schäffer zu fragen, was an seiner Einstellung auf das Konto einer CSU-spezifischen Haltung zur Wiedergutmachung ging und was den Auswirkungen seines Amtes als Finanzminister anzurechnen war. Dafür, daß Schäffers fortgesetzte Gegnerschaft zu allen Wiedergutmachungsleistungen durch den Bund sozusagen das Ergebnis einer unparteiischen, quasi ressortimmanenten Sparsamkeit entsprang, könnte man etwa das Resultat einer Gegenprobe anführen: Er widersetzte sich sehr wohl auch solchen Ausgaben, die nichts mit der Wiedergutmachung zu tun hatten, mit einer gleichartigen Hartnäckigkeit. Problematisch im Sinne einer politisch-moralischen Bewertung seines Verhaltens ist jedoch, daß Schäffer bei seinen Einsparungsbemühungen kaum bereit war, einen kategorialen Unterschied zwischen den finanziellen Konsequenzen etwa aus der Senkung der Kaffee- und Teesteuer und aus der Entschädigung für Verfolgte des Nationalsozialismus zu machen ${ }^{97}$.

Neben die Sachlogik des Finanzressorts traten mitunter aber auch Elemente eines traditionellen antijüdischen Weltbildes: So erteilte Schäffer im März 1952 allen Oberfinanzdirektionen den Auftrag, eine Schätzung über die von Juden nach dem Krieg begangenen Steuer- und Devisenvergehen auf dem Gebiet der Bundesrepublik zu erstellen, um so den jüdischen Wiedergutmachungsforderungen eine Zahl über die von dieser Seite erfolgte Schädigung der deutschen Volkswirtschaft entgegenhalten zu kön-

93 Karl Marx an Thomas Dehler, 11.11. 1950, BA, B 126/12360.

94 Siehe etwa Adenauer an Dehler, 1. 12. 1950, AdL, N 1/3151; Dehler an Wilde (Bundeskanzleramt), 5. 2. 1951, ebenda; Dehler an Blücher, 5.7. 1951, ebenda. Siehe auch Blücher in der FDP-Vorstandssitzung am 20.9. 1951, in: FDP-Bundesvorstand. Die Liberalen unter dem Vorsitz von Theodor Heuss und Franz Blücher. Sitzungsprotokolle 1949-1954, bearbeitet von Udo Wengst, Erster Halbband, 1.-26. Sitzung, 1949-1952, Düsseldorf 1990, S. $280 \mathrm{f}$.

95 Deutscher Bundestag, 165. Sitzung vom 27.9. 1951, Stenographische Berichte, Bd. 9, S.6697f.

96 Siehe dazu Sechstes Kapitel.

97 Sondersitzung des Kabinetts am 20.5. 1953, Die Kabinettsprotokolle der Bundesregierung, Bd. 6: 1953, bearb. v. Ulrich Enders u. Konrad Reiser, hrsg. f. d. Bundesarchiv v. Hans Booms, Boppard a. Rh. 1989, S. $303 \mathrm{f}$. 
nen ${ }^{98}$. Gegen die daraus entstandene Schätzung, die auf höchst fragwürdige Weise zu dem Ergebnis kam, daß „die Juden“ seit der Währungsreform den deutschen Fiskus um mehr als zehn Mrd. DM betrogen hätten, rebellierte schließlich das Wiedergutmachungsressort des Bundesfinanzministeriums. Ministerialrat Magen wies Schäffer auf die verheerenden Wirkungen hin, die bei Bekanntwerden „dieser gegen die Juden gerichteten amtlichen Maßnahmen“ zu erwarten seien. „Auf die Frage“, so Magen, „in welchem Umfang auch bei amtlichen Stellen durch diese Statistiken der Antisemitismus gefördert werden wird, in dieser Vorlage einzugehen, möchte ich mir versagen." 99 Düpiert ließ Schäffer daraufhin dieses heiße Eisen fallen ${ }^{100}$. Wenngleich dieser Vorfall das Fortbestehen antijüdischer Vorurteile überdeutlich zeigt, wird daraus doch auch ersichtlich, daß sich mit solchen in der Bundesrepublik - wenigstens offiziell - keine Politik mehr machen ließ.

Wie dünn das Eis war, auf dem sich viele Politiker noch bewegten, wurde auch bei der FDP sichtbar. Dort prägte neben Vizekanzler Blücher insbesondere Bundesjustizminister Dehler das Bild seiner Partei in der Frage der Wiedergutmachung. Einen tieferen Einblick in seine Einstellung zur Wiedergutmachung gab er auf der Arbeitstagung jüdischer Juristen im Bundesgebiet und Berlin im Dezember 1951, als er sich gegen Vorwürfe des stellvertretenden amerikanischen Hohen Kommissars verteidigte. Buttenwieser hatte kritisiert, daß nicht versucht werde, das Naziunrecht wiedergutzumachen, außerdem sei es erschütternd, daß sich das deutsche Volk nicht gegen Männer wie Dehler in der Regierung auflehne. Dieser hielt beleidigt dagegen: „Es wäre viel mehr Möglichkeit in Deutschland gewesen, das was unsere Pflicht ist zu tun, wenn nicht eine verhängnisvolle Politik uns gehemmt hätte, eine Politik der Alliierten ... Und es ist für mich bitter ..., daß immerhin unter dem Namen eines jüdischen Politikers, Morgenthau, jahrelang Politik gemacht wurde ... Welche Möglichkeiten wurden dem deutschen Volke mit solchen Maßnahmen genommen, seine Pflicht zu erfüllen, wieder gutzumachen. “ ${ }^{101}$ Dehler verwies überdies auf die schweren sozialen Lasten, die die Bundesrepublik zu tragen hatte, namentlich die Versorgung der ca. 10 Mio. Vertriebenen ${ }^{102}$. Daß er hier also mangelndes deutsches Engagement bei der Wiedergutmachung auf eine quasi jüdisch inspirierte alliierte Politik zur Vernichtung der deutschen wirtschaftlichen Leistungskraft zurückführte, sorgte für einige Aufregung ${ }^{103}$.

Zugleich hatte Dehler aber auch die Verpflichtung des deutschen Volkes zur Wiedergutmachung insbesondere an den Juden unterstrichen, wobei er eine schicksalhafte Verkettung dieser beiden Völker annahm: „Eine meiner Erkenntnisse in dieser verruchten Nazizeit, alles was das deutsche Volk den Juden antat, geschah ihm wieder. Man nahm den Juden die politische Freiheit, und das deutsche Volk verlor die Freiheit; man nahm den Juden das Leben, Millionen Deutsche verloren das Leben, man nahm ihnen Hab und Gut, und Millionen Deutsche verloren Hab und Gut." Aus dieser angenommenen deutsch-jüdischen Schicksalsgemeinschaft folgerte Dehler schließlich für die

\footnotetext{
98 Ministerialrat Hans Gurski an Schäffer, 12.5. 1952, BA, B 126/51544; vgl. dazu auch Christian Pross, Wiedergutmachung. Der Kleinkrieg gegen die Opfer, Frankfurt a.M. 1988, S. 65.

99 Ministerialrat Magen an Schäffer, 21.5. 1952, BA, B 126/51544.

100 Schäffer an Abteilungen V und VI des Bundesfinanzministeriums, 24.5. 1952, BA, B 126/51544.

$10 t$ Die Arbeitstagung jüdischer Juristen im Bundesgebiet und Berlin am 15. und 16. Dezember 1951 in Düsseldorf, Sonderveröffentlichung der Allgemeinen Wochenzeitung der Juden in Deutschland, S. $23 \mathrm{f}$.

102 Dehler an die Arbeitstagung jüdischer Juristen, 17. 12. 1951, ebenda, S. 63.

103 Siehe dazu die Dokumentation, ebenda.
} 
Zukunft: „Es gilt, was gesagt wurde, dem deutschen Volk wird widerfahren, was es auch jetzt tut, an ihm wird nur vom Schicksal wiedergutgemacht werden, was es den Juden wieder gutmacht. “ ${ }^{104}$ Wiedergutmachung für die Juden war damit bei Dehler die Voraussetzung der geforderten Wiedergutmachung für die Deutschen.

Bei Dehler resultierte aus dieser schicksalhaften Verknüpfung der deutschen und jüdischen Geschichte immerhin noch die Forderung, daß der erste Schritt Wiedergutmachung für die Juden sein müsse, und tatsächlich gehörte Dehler wenigstens partiell zu den Förderern einer aktiven Wiedergutmachungspolitik ${ }^{105}$. Im Kreise der rechtskonservativen DP wurde aus der hier zugrundeliegenden Gleichsetzung des deutschen und jüdischen Schicksals dann schon eher ein Aufrechnen und die geforderte Reihenfolge der Wiedergutmachung demzufolge gerade umgekehrt. So schrieb Bundesverkehrsminister Hans-Christoph Seebohm im Mai 1952 an Franz Böhm: „Wenn ich jederzeit bereit bin, die sittliche Wiedergutmachungspflicht gegenüber der Judenschaft anzuerkennen, so kann ich das nur tun, wenn auch die übrigen Kräfte in der Welt bereit sind, ihre sittliche Wiedergutmachungspflicht gegenüber den deutschen Heimatvertriebenen zu erfüllen ... Die Methoden, die seitens (sci. der) nationalsozialistischen Führung gegen die Juden angewandt wurden und die wir alle auf das erbittertste verurteilen, stehen deshalb durchaus den Methoden zur Seite, die gegen die deutschen Heimatvertriebenen angewandt worden sind. " 106 Dies bedeutete, wie Michael Wolffsohn zutreffend bemerkte, die Gleichsetzung von Holocaust und Vertreibung ${ }^{107}$, aber auch die Priorität der Wiedergutmachung für die deutschen Heimatvertriebenen.

Auf Seiten der Opposition äußerte hingegen die SPD ein kontinuierliches und großes Interesse an der Wiedergutmachung. Wie geschildert, hatten bereits während des Krieges erste diesbezügliche Überlegungen im sozialdemokratischen Exil eingesetzt. Nach dem Krieg griff insbesondere der Vorsitzende der SPD Kurt Schumacher diese Frage wiederholt auf. In ersten Stellungnahmen warf er die Wiedergutmachung für Verfolgte des Nationalsozialismus allerdings in eins mit den Reparationen für andere Staaten, wobei es ihm auch darum ging festzustellen, „daß die Grenzen jeder Wiedergutmachung in der Erhaltung der letzten Lebensnotwendigkeiten des eigenen Volkes liegen “ ${ }^{108}$. Doch auf dem zweiten Parteitag der SPD Ende Juni 1947 in Nürnberg unterstrich Schumacher unter besonderer Hervorhebung der jüdischen Opfer des Nationalsozialismus die Verpflichtung des deutschen Volkes zur Wiedergutmachung und Entschädigung. Daß bislang in dieser Richtung zu wenig geschehen sei, lastete er aber, ähnlich wie später Dehler, in erster Linie dem Versagen der Alliierten an, denen keine Einigung in dieser Frage geglückt sei ${ }^{109}$.

Auch in einem Interview mit dem in New York erscheinenden Aufbau wiederholte er dieses Argument und fügte hinzu, daß „durch den Mangel an Direktion ... der gesamte moralische Gedanke der Wiedergutmachung völlig unterminiert worden“ sei. In der Sprache Schumachers erschien das deutsche Volk somit als ein Kind, das eine

104 Begrüßungsansprache Dehlers, ebenda, S. $25 \mathrm{f}$.

$105 \mathrm{Vgl}$. Sechstes Kapitel.

106 Seebohm an Böhm, 21.5. 1952, BA, B 136/1127.

$107 \mathrm{Vgl}$. Wolffsohn, Globalentschädigung für Israel und die Juden, S. 178.

108 Aufruf Kurt Schumachers vom Sommer 1945, „Konsequenzen deutscher Politik“, in: Kurt Schumacher, Reden und Schriften, hrsg. v. Arno Scholz und Walther G. Oschlewski, Berlin 1962, S. $41 \mathrm{f}$.

109 Protokoll der Verhandlungen des Parteitages der Sozialdemokratischen Partei Deutschlands vom 29.6. -2.7. 1947 in Nürnberg, Hamburg 1947, S. 50 f. 
elterliche Bestrafung erwartete und nach deren Ausbleiben alsbald jegliches Schuldgefühl abschüttelte. Doch änderte er hier anscheinend seine Auffassung, denn auf dem dritten SPD-Parteitag im Sommer 1948 bedauerte Schumacher in seinem (wegen Krankheit von Andreas Gayk verlesenen) Referat „das Fehlen eines deutschen Initiativwillens" in der Behandlung der Wiedergutmachung als etwas, „das auf mitfühlende Menschen beschämend wirken und dem deutschen Volk in der Weltöffentlichkeit Schaden bringen muß ${ }^{\prime 110}$.

Neben der Tatsache, daß zahlreiche Sozialdemokraten selbst verfolgt worden waren, bildete auch die Bedeutung der Wiedergutmachungsfrage für die internationalen Beziehungen der SPD ein wichtiges Motiv für ihr Engagement auf diesem Feld. Einerseits spielte sie eine gewisse Rolle auf dem dornigen Weg zur Wiederaufnahme der SPD in die Sozialistische Internationale. Zugleich war sie auch von großer Bedeutung für die erstrebte Anerkennung durch die amerikanischen Gewerkschaften ${ }^{111}$. Im September/ Oktober 1947 reisten Kurt Schumacher und Fritz Heine auf Einladung der American Federation of Labor (AFL) durch die USA, und bei dieser Gelegenheit trafen sie unter anderem auch mit Vertretern des American Jewish Committee sowie des Jewish Labor Committee, einer amerikanischen jüdischen Gewerkschaftsorganisation, zusammen ${ }^{112}$. Den Höhepunkt dieser Reise bildete eine Rede Schumachers auf dem Jahreskongreß der AFL in San Francisco. Dort bekräftigte er (unter Auslassung der Vorwürfe an die Besatzungsmächte) namens seiner Partei, „daß das deutsche Volk zur Wiedergutmachung und Entschädigung an die Juden verpflichtet ${ }^{\star 113}$ sei.

Unter dem Einfluß der Versuche der SPD, wieder in den Kreis der internationalen sozialistischen Organisationen aufgenommen zu werden bzw. Anerkennung durch die amerikanischen Gewerkschaften zu erhalten, war also auch hier besonders die Frage der Wiedergutmachung für die Juden stark akzentuiert worden. Die jüdischen Organisationen versuchten in der Folge, diesen Faden aufzugreifen. Ende 1948 reiste Max Isenbergh im Auftrag des American Jewish Committee mit der Absicht nach Westdeutschland, bei den laufenden Beratungen des Parlamentarischen Rates in Bonn die Aufnahme einer Klausel in das Grundgesetz zu erreichen, mit der die moralische Notwendigkeit der Rückerstattung und Entschädigung für Verfolgte des Nationalsozialismus dort verankert werden sollte. Die - letztlich vergeblichen - Hoffnungen konzentrierten sich dabei auf die SPD ${ }^{114}$.

Zu diesem Zweck führte Isenbergh zusammen mit Zachariah Shuster im Januar 1949 eine Reihe von Gesprächen mit hochrangigen Funktionären der SPD sowie der Gewerkschaften, darunter Georg Reuter, Generalsekretär des bayerischen Gewerkschaftsbundes, Fritz Heine und Erich Ollenhauer aus dem SPD-Parteivorstand ${ }^{115}$. Im Gegenzug für die erbetene Unterstützung der Rückerstattung und Entschädigung boten sie

110 Protokoll der Verhandlungen des Parteitages der Sozialdemokratischen Partei Deutschlands vom 11. bis 14. 9. 1948 in Düsseldorf, Hamburg 1948, S. 33.

111 Vgl. Shlomo Shafir, Die SPD und die Wiedergutmachung gegenüber Israel, in: Herbst/Goschler (Hrsg.), Wiedergutmachung, S. 194f; ders., Kurt Schumacher und die Juden, in: Tribüne 28 (1989), S. 131-133.

112 Schumacher an Erich Ollenhauer aus San Francisco: Bericht über die ersten Wochen des USA-Besuches, 7. 10. 1947, in: Schumacher. Reden - Schriften - Korrespondenzen, hrsg. v. Willy Albrecht, Bonn 1985, S. 559-562; ebd., Vorbemerkungen von W. Albrecht, S. $131 \mathrm{f}$.

113 Rede Schumachers am 14.10. 1947 auf dem Jahreskongreß der AFL in San Francisco, ebd., S. 565.

${ }^{114}$ Max Isenbergh an das Foreign Affairs Department des American Jewish Committee, 27. 12. 1948, YIVOArchiv, RG 347, AJC, Records GEN-10, Box 282.

115 Isenbergh an Foreign Affairs Department des AJC, Memorandum über Gespräche mit SPD-Führern in Deutschland, 10.1. 1949, YIVO-Archiv, RG 347, AJC, Records GEN-10, Box 280. 
ihnen Hilfe bei der Verbesserung des Verhältnisses zu den amerikanischen Gewerkschaften an ${ }^{116}$. Die Angesprochenen reagierten positiv, und Fritz Heine versprach, daß die SPD in den Beratungen des Parlamentarischen Rates einen entsprechenden Versuch zur Verankerung einer Wiedergutmachungsklausel im Grundgesetz unternehmen wolle ${ }^{117}$.

Dieser Vorstoß des American Jewish Committee über eine deutsche Partei demonstriert erneut die veränderten politischen Rahmenbedingungen der Wiedergutmachung. In den ersten Nachkriegsjahren hatten sich die jüdischen Anstrengungen auf die Militär- bzw. die alliierten Regierungen konzentriert. Nun wurde es für die jüdischen Organisationen zunehmend erforderlich, auch an die Deutschen selbst heranzutreten, da die Amerikaner ebenso wie die anderen Westmächte nicht mehr bereit schienen, sich in dieser Frage übermäßig zu exponieren. So empfahl Isenbergh, künftig eine Art Doppelstrategie zu verfolgen, wonach die Deutschen mit Hilfe der Alliierten und die Alliierten mit Hilfe der Deutschen zur Unterstützung der jüdischen Wiedergutmachungsforderungen bewegt werden sollten ${ }^{118}$.

Die SPD jedenfalls blieb sich ihrer Rolle als Fürsprecher der Wiedergutmachung, insbesondere für die Juden, auch in der Bundesrepublik treu. Schumacher kritisierte heftig, daß Adenauer in seiner ersten Regierungserklärung zwar alle möglichen Kategorien von Geschädigten ausdrücklich erwähnt hatte, aber nicht auf die deutschen Verfolgten des Nationalsozialismus eingegangen war, die „doch zu den wenigen außenpolitischen Aktiven des deutschen Volkes und der deutschen Außenpolitik" gehörten. Als „zu matt und zu schwach“ befand Schumacher insbesondere auch, was Adenauer dort „über die Juden und über die furchtbare Tragödie der Juden im Dritten Reich gesagt“ habe $^{119}$.

Zwar engagierte sich die SPD als einzige der im Bundestag vertretenen Parteien geschlossen für die Wiedergutmachung. Zugleich existierte aber auf der Ebene unterhalb der Parteiführer teilweise eine "große Koalition“ der Wiedergutmachungsbefürworter, die sich nicht an Parteigrenzen orientierte. Dazu gehörten auf Seiten der SPD inbesondere Adolf Arndt, Otto-Heinrich Greve sowie Jakob Altmaier (einer der wenigen jüdischen Bundestagsabgeordneten $)^{120}$, auf Seiten der Union vor allem Franz Böhm und Eugen Gerstenmaier ${ }^{121}$. Auch Bundespräsident Theodor Heuss spielte wiederholt eine positive Rolle in dieser Angelegenheit ${ }^{122}$. Hierin kam erneut zum Ausdruck, daß die Bemühungen um die Wiedergutmachung auf deutscher Seite häufig den Zug eines ausgeprägten Einzelkämpfertums trugen, wie auch an den Gestalten Otto Küsters und Philipp Auerbachs zu sehen war.

\footnotetext{
116 Isenbergh an Eugen Hevesi (AJC), 28. 1. 1949, YIVO-Archiv, RG 347, AJC, Records GEN-10, Box 280.

117 Isenbergh an Foreign Affairs Department/AJC, 10.1. 1949, YIVO-Archiv, RG 347, AJC, Records GEN-10, Box 280; Fritz Heine an Z. Shuster und Isenbergh, 25. 1. 1949, ebenda.

118 Ebenda.

119 Deutscher Bundestag, 6. Sitzung am 21.9. 1949, Stenographische Berichte, Bd. 1, S. 36.

120 Vgl. dazu Willy Albrecht, Ein Wegbereiter: Jakob Altmaier und das Luxemburger Abkommen, in: Herbst/ Goschler (Hrsg.), Wiedergutmachung, S. 205-213.

121 Vgl. dazu Sechstes Kapitel.

122 Siehe dazu etwa McCloy an Acheson, 2. 10. 1951, WNRC, RG 466, Records of the U.S. High Commissioner for Germany (McCloy Papers), Box 32; AJC Contributions to Postwar Economic Rehabilitation of Jewish Victims of Nazi Persecution, September 1965, AJC-Archiv, JSX, Subject Restitution 65-66.
} 


\section{Die christlichen Kirchen: Von der Judenmission zur Wiedergutmachung für Israel}

Bei einem Thema, das sich so sehr auf dem Grat zwischen Politik und Moral bewegt wie die Wiedergutmachung, scheint die Frage legitim, in welcher Weise sich die christlichen Kirchen, die für die Vermittlung ethischer Kategorien in der deutschen Gesellschaft zwar längst nicht mehr das Monopol, doch immer noch große Bedeutung besitzen, damit befaßten. Gewiß sollte man den in anderem Zusammenhang vorgebrachten methodischen Einwand Heinz Hürtens beherzigen, daß "nicht eine irgendwie moralisch begründete Erwartung" die Interpretation des kirchlichen Verhaltens bestimmen dürfe ${ }^{123}$. Aber angesichts der Tatsache, daß nach einer anfänglichen Stille seit etwa 1949/50 zunehmend kirchliche Stimmen zugunsten der Wiedergutmachung für Verfolgte des Nationalsozialismus laut wurden, ist die Frage berechtigt, warum gerade da und nicht bereits vorher. Eine grundsätzliche Feststellung läßt sich dabei sowohl für die katholische als auch die evangelische Kirche treffen: Ihre Auseinandersetzung mit der Frage der Wiedergutmachung bezog sich zunächst primär auf die jüdischen Verfolgten. Hierin liegt auch bereits ein wesentlicher Grund für das verzögerte Einsetzen dieser Debatte: Beide Kirchen mußten sich hier der heiklen Frage nach der Bedeutung der traditionellen christlichen Judenfeindschaft für den rassistischen Antisemitismus in der NS-Zeit stellen. Die Beschäftigung mit diesem Thema fiel so zum Teil auch mit der eigenen Vergangenheitsbewältigung zusammen.

Diese Schwierigkeiten waren auf protestantischer Seite besonders groß, hatte sich doch im Dritten Reich unter der von den „Deutschen Christen“ beherrschten Mehrheit gar kein und auch innerhalb der „Bekennenden Kirche“, die eine distanziertere Stellung zum Nationalsozialismus eingenommen hatte, nur vereinzelter Widerspruch gegen die Judenverfolgung geregt. Die Ambivalenz des Protestantismus zwischen partieller Opposition und einer generell starken Verhaftung mit national-konservativen und auch völkischen Ideen ${ }^{124}$ personifizierte sich etwa in Martin Niemöller, der das NS-Regime ursprünglich begeistert begrüßt hatte, sich dann über kirchliche Fragen zum aktiven Gegner Hitlers wandelte, deshalb 1937 verhaftet wurde und 1938 bis 1945 als Sonderhäftling in Sachsenhausen und Dachau verbrachte. Während er im Ausland als Symbol des deutschen Widerstands galt, lehnte zugleich die VVN seine Mitgliedschaft ab, nachdem er in einem Interview u. a. erklärt hatte, bei Kriegsausbruch vom KZ aus den Antrag auf Einberufung in die Kriegsmarine gestellt zu haben. Als sich die hessische KZ-Betreuungsstelle Büdingen deshalb im Sommer 1947 vorübergehend weigerte, ihm die Verfolgten zustehenden Sonderrechte zuzuerkennen, beschwerte sich Niemöller: „Sie unterstützen wohl nur Judenfreunde?" 125

Niemöller wiederum war es, der den entscheidenden Anstoß zu dem berühmten Stuttgarter Schuldbekenntnis gab, das anläßlich der Tagung des Rates der Evangelischen Kirche in Deutschland (EKD) im Oktober 1945 in Stuttgart entstand. Dort hieß

${ }^{123}$ Heinz Hürten, Katholische Kirche und nationalsozialistischer Krieg, in: Die deutschen Eliten und der Weg in den Zweiten Weltkrieg, hrsg. v. Martin Broszat usw., München 1989, S. 137.

124 Vgl. Werner Jochmann, Evangelische Kirche und politische Neuorientierung in Deutschland 1945, in: Deutschland in der Weltpolitik des 19. u. 20. Jahrhunderts, hrsg. v. Immanuel Geiss u. Bernd Jürgen Wendt, Düsseldorf 1973, S.548ff.

125 R. Wallach an Director, PW \& DP Division/OMGUS, Report on Pastor Niemöller, 22. 8. 1947, IfZ-Archiv, MF 260, OMGH, 8/66-2/1. Vgl, auch Der Spiegel, Nr. 32, 9.8. 1947, S. 4, „Nur Judenfreunde. Zusatzkarte für Martin Niemöller“; Dietmar Schmidt, Martin Niemöller. Eine Biographie, Stuttgart '1983, S. 102 f. 
es unter anderem, daß „durch uns ... unendliches Leid über viele Völker und Länder gebracht worden“ sei, „wir klagen uns an, daß wir nicht mutiger bekannt, nicht treuer gebetet, nicht fröhlicher geglaubt und nicht brennender geliebt haben " ${ }^{126}$. So allgemein diese Erklärung auch gehalten war, ging sie vielen deutschen Protestanten sowohl an der Basis als auch in der Kirchenleitung noch zu weit ${ }^{127}$. Eine Minderheit kritisierte aber auch, daß kein Bezug insbesondere auf die Verbrechen an den Juden erfolgt war. So befaßte sich der Bruderrat der Evangelischen Kirche in Deutschland auf einer Tagung am 8. April 1948 speziell mit der „Judenfrage“. Die beklagten Verbrechen an den Juden wurden dabei in der theologischen Perspektive des christlichen Auftrags zur Judenmission behandelt: „Daß Gott nicht mit sich spotten läßt, ist die stumme Predigt des jüdischen Schicksals, uns zur Warnung, den Juden zur Mahnung, ob sie sich nicht bekehren möchten zu dem, bei dem allein ihr Heil steht. “ ${ }^{128}$ Diese Tendenz, den Holocaust als heilsgeschichtliche Etappe einzuordnen, korrespondierte übrigens auch mit der Holocaust-Deutung einer orthodox-jüdischen Minderheit ${ }^{129}$.

Doch hatte ja im Dritten Reich anders als im Mittelalter der Übertritt zum Christentum gerade nicht vor Verfolgung geschützt. Die evangelische Kirche nahm angesichts des 1933 einsetzenden Terrors auch gegen Christen jüdischer Herkunft eine zwiespältige Haltung ein. Während sich aber die offiziellen Organe der Evangelischen Kirche in Deutschland von diesem Problem distanzierten, unternahm die „Bekennende Kirche“ zum Teil Anstrengungen, den rassisch verfolgten evangelischen Christen zu helfen. Aus diesem Engagement für die sogenannten „Christenjuden“ in der NS-Zeit entwickelten sich aber auf protestantischer Seite nach dem Krieg erste Anstöße für eine Beschäftigung mit dem Wiedergutmachungsproblem. Probst Heinrich Grüber, während des Dritten Reichs Leiter des sogenannten Büro Grüber, das vor allem rassisch verfolgten evangelischen Christen bei der Auswanderung zu helfen versucht hatte ${ }^{130}$, kritisierte im März 1949 öffentlich, daß die evangelische Kirche in Deutschland zwar zu „mancherlei Nöten und Fragen der Zeit Stellung genommen habe“, doch sei „von keiner kirchenamtlichen Stelle ein grundsätzliches Wort zur Wiedergutmachungsfrage gesagt worden"131. Dies bewahrheitete sich erneut auf der Synode der EKD in Weißensee vom 23.-27. April 1950, wo zwar ein „Wort zur Judenfrage“ beschlossen, die Frage der Wiedergutmachung aber wiederum ausgespart wurde.

Innerhalb der Hierarchie der EKD dominierte in dieser Zeit die Befürchtung, beim Kirchenvolk auf Ablehnung für derartige Forderungen zu stoßen. So entschuldigte das

${ }^{126}$ Erklärung des Rates der Evangelischen Kirche in Deutschland gegenüber den Vertretern des Ökumenischen Rates der Kirchen, 19. 10. 1945, Kirchliches Jahrbuch für die Evangelische Kirche in Deutschland 1945-1948, 72.-75. Jg., Gütersloh 1950, S. 26.

127 Vgl. etwa Jochmann, Evangelische Kirche und politische Neuorientierung, S. $558 \mathrm{f}$.

128 Wort des Bruderrates der Evangelischen Kirche in Deutschland zur Judenfrage, Darmstadt, 8. 4. 1948, Kirchliches Jahrbuch für die Evangelische Kirche in Deutschland 1945-1948, S. 224-227, hier: S. 225. Vgl. auch (ebenda, S. 222f.) das „Anschreiben an die Pfarrämter wegen der Verpflichtung der Gemeinden gegenüber den Juden“ von Oberkirchenrat Stählin (Oldenburgische Kirche) vom 6.12. 1947, in der diese Argumentation bereits vorgezeichnet ist.

${ }^{129}$ Vgl. Michael Wolffsohn, Ewige Schuld? 40 Jahre Deutsch-Jüdisch-Israelische Beziehungen, München u. Zürich ${ }^{2} 1988$, S. 67.

130 Vgl. Probst Heinrich Grüber, Erinnerungen aus sieben Jahrzehnten, Köln u. Berlin 1968, S. 103-145; JochenChristoph Kaiser, Protestantismus, Diakonie und „Judenfrage“ 1933-1941, in: Vierteljahrshefte für Zeitgeschichte (VfZ) 37 (1989), S. $702 \mathrm{f}$.

131 Vgl. Propst H. Grüber, 8. 3. 1949, Kirche und Wiedergutmachung, in: Rundbrief zur Förderung der Freundschaft zwischen dem alten und dem neuen Gottesvolk - im Geiste der beiden Testamente (Freiburger Rundbrief), Nr.4, Juli 1949, S. 12. 
Kirchliche Jahrbuch der EKD für 1953 die bisherigen bescheidenen Anstrengungen auf diesem Gebiet in folgender Weise: „Die Kirche mußte ja auch die seelische und wirtschaftliche Lage des Volkes, zu dem sie sprach, im Auge haben, wenn sie nicht völlig in den Wind reden wollte. Die Masse des deutschen Volkes sah sich in den ersten Jahren nach dem Zusammenbruch durch Hungersnot, Reparationen und Demontagen, durch Kriegsschäden und Flüchtlingselend ständig in der nackten Existenz bedroht und war auf Mahnungen zu größeren Opfern überhaupt nicht ansprechbar. Darum konnte zunächst wohl auch die Kirche nicht mehr von ihren Gliedern erwarten als Beweise des guten Willens und der Einsicht, daß man die Wiedergutmachungsfrage nicht stillschweigend auf sich beruhen lassen durfte. " 132 Im Mittelpunkt der Argumentation stand also die Schonung eines Volkes, das gerade damit beschäftigt war, seine eigenen Wunden zu lecken. Offensichtlich bestand keine große Neigung, die scheinbare Gunst der Stunde, die Stellung der Kirche in der Gesellschaft zu stärken, durch unpopuläre Forderungen aufs Spiel zu setzen. Dies führte insgesamt zu dem Ergebnis, daß die evangelische Kirche die erste Zeit nach dem Krieg zwar energisch für die Betroffenen der Entnazifizierung und auch für verurteilte Kriegsverbrecher eintrat, nicht aber für die Opfer der nationalsozialistischen Verfolgung ${ }^{133}$.

$\mathrm{Daß}$ sich hier zumindest eine partielle Wandlung ergab, hatte wiederum mit der Auseinandersetzung mit dem christlich-jüdischen Verhältnis zu tun, die auch in der evangelischen Kirche von einigen engagierten Kreisen betrieben wurde. So trat der „Deutsche evangelische Ausschuß für Dienst an Israel“ Anfang März 1951 an die Bundesregierung mit der Bitte heran, „die Wiedergutmachung nationalsozialistischen Unrechts, das in seinem stärksten Ausmaße den Juden und den ihnen durch die Nürnberger Rassegesetze Gleichgestellten zugefügt wurde, als ganz besonders dringlich zu behandeln " ${ }^{134}$. Auch der Rat der EKD unterstützte dieses Schreiben durch Eingaben in diesem Sinne ${ }^{135}$. Allerdings galt hier die besondere Aufmerksamkeit den Protestanten jüdischer Abstammung, für die sich der Rat der Evangelischen Kirche speziell im Zusammenhang der Verhandlungen mit Israel und der Claims Conference in Wassenaar 1952 einsetzte, da diese die sogenannten Nicht-Glaubensjuden nicht berücksichtig$\operatorname{ten}^{136}$. Juden und Christen verhielten sich in dieser Frage sehr ähnlich und konzentrierten die Bemühungen in erster Linie auf die Angehörigen ihres eigenen Glaubens.

Vergleicht man damit die Entwicklung auf Seiten der katholischen Kirche, findet man neben Parallelen auch einige Unterschiede. Auch hier bildete die intensivierte Auseinandersetzung mit dem christlich-jüdischen Verhältnis angesichts der vergangenen nationalsozialistischen Verbrechen den zentralen Zugang zur Frage der Wiedergutmachung. Wiederum waren es vor allem Kreise, die bereits im Dritten Reich versucht hatten, (katholischen) rassisch Verfolgten zu helfen, die hier den Hauptmotor bildeten. Gertrud Luckner, die in jener Zeit eine Hilfsstelle geleitet hatte, die auf katholischer

132 Kirchliches Jahrbuch für die Evang. Kirche in Deutschland 1953, 80. Jg., Gütersloh 1954, „Die Lage nach 1945. Schuldfrage und Wiedergutmachungsproblem", S. 307.

133 Vgl. Clemens Vollnhals, Die Evangelische Kirche zwischen Traditionswahrung und Neuorientierung, in: Von Stalingrad zur Währungsreform. Zur Sozialgeschichte des Umbruchs in Deutschland, hrsg. v. Martin Broszat, Klaus-Dietmar Henke u. Hans Woller, München 1988, S. $142 \mathrm{f}$.

134 Kirchliches Jahrbuch für die Evang. Kirche in Deutschland 1953, S. 308, dort Wortlaut des Schreibens abgedruckt.

135 Ebenda.

136 Ebenda, S. 309 f. 
Seite ähnliche Aufgaben wie das Büro Grüber auf protestantischer übernahm, und deshalb 1943 verhaftet wurde, setzte nach dem Krieg ihre Tätigkeit in einer Arbeitsstelle für ehemals vom Nationalsozialismus Verfolgte fort. Um sie herum bildete sich ein Arbeitskreis, der sich der grundsätzlichen Frage des christlich-jüdischen Verhältnisses widmete. Zu diesem Zweck wurde auch eine eigene Zeitschrift mit dem programmatischen Titel Rundbrief zur Förderung der Freundschaft zwischen dem alten und dem neuen Gottesvolk gegründet, nach ihrem Erscheinungsort auch kurz Freiburger Rundbrief genannt ${ }^{137}$. Sie wurde zu einem Podium der christlichen Diskussion über das Verhältnis zu den Juden bzw. zur Wiedergutmachung an ihnen und anderen Verfolgten.

Da die katholische Kirche nach dem Krieg nicht wie die evangelische durch eine von schweren inneren Auseinandersetzungen über die eigene Vergangenheit begleitete Neuorganisation belastet war, fiel es ihr leichter, sich mit diesen Fragen zu beschäftigen. Bereits im September 1948 kam eine erste offizielle katholische Stellungnahme zum christlich-jüdischen Verhältnis zustande, bei der auch die Wiedergutmachung angesprochen wurde. In einer vom 72. Deutschen Katholikentag in Mainz beschlossenen Erklärung hieß es: „Das geschehene Unrecht fordert Wiedergutmachung im Rahmen des Möglichen. Es handelt sich hierbei nicht bloß um die gerechte Verteilung vorhandener Güter, sondern um die Rückgabe widerrechtlich entwendeter." Auch hier wurde ein Aufruf gegen den Antisemitismus an die Gläubigen gerichtet, der wiederum auf der durch den Apostel Paulus ausgesprochenen Erwartung beruhte, daß sich das jüdische Volk eines Tages zum Christentum bekehren würde (Roemer 11, $25 \mathrm{ff}$.) ${ }^{138}$. Diese Erklärung zur Wiedergutmachung bildete den Gegenpol zur gleichzeitig erhobenen Forderung nach einem abschließenden „Versöhnungsgesetz“, durch welches ein Schlußstrich unter die als gescheitert bezeichnete Entnazifizierung gezogen werden sollte ${ }^{139}$. Versöhnungsgesetz und Wiedergutmachung als korrespondierende Maßnahmen sollten die Vorbedingung für die innere Befriedung der deutschen Gesellschaft leisten. Im kirchlichen, sozusagen vorpolitischen Raum wurde so eine Forderung formuliert, die in der folgenden Zeit erhebliche politische Bedeutung erlangte ${ }^{140}$.

Zwar waren es auch auf katholischer Seite eher nur kleine Zirkel, die sich dieser Frage aktiv annahmen, doch immerhin erreichten sie, daß die Wiedergutmachung auf der Tagesordnung blieb, wobei weiterhin in erster Linie das Verhältnis zu den Juden im Mittelpunkt stand. So erarbeitete die Freiburger Arbeitsgruppe Anfang 1951 eine „Katechese über Christenheit und jüdisches Volk“, die mit Billigung der meisten katholischen Bischöfe an alle katholischen Pfarrer und hauptberuflichen Religionspädagogen in Deutschland verschickt wurde. Darin wurde auch versucht, weitverbreitete Vorurteile gegenüber der Wiedergutmachung an den Juden zu bekämpfen. Als Beispiele solcher Vorurteile wurde etwa zitiert: „'Ansprüche bestehen nicht, da die Flüchtlinge auch nichts bekommen' (Bayr. Witwe mittleren Alters); 'Erst soll man gegen die Deut-

137 Gertrud Luckner, Memorandum über die Tätigkeit der Arbeitsstelle für ehemals vom Nationalsozialismus Verfolgte, in: Freiburger Rundbrief, Nr.4, Juli 1949, S. 19. Zu den katholischen Hilfsmaßnahmen für NSVerfolgte vgl. auch Lutz-Eugen Reutter, katholische Kirche als Fluchthelfer im Dritten Reich. Die Betreuung von Auswanderern durch den St.Raphaels-Verein, Recklinghausen-Hamburg 1971.

138 Entschließung des Deutschen Katholikentages zur Judenfrage, in: Der Christ in der Not der Zeit. Der 72. Deutsche Katholikentag vom 1. bis 5. September 1948 in Mainz, hrsg. v. Generalsekretariat des Zentralkomitees der Katholiken Deutschlands zur Vorbereitung der Katholikentage, Paderborn 1949, S. 330.

139 Freiburger Rundbrief, Nr. 5/6, Dezember 1949, „Mainz 1948 - Bochum 1949“, S. 5 f.

140 Vgl. Sechstes Kapitel, Abschnitt IV. 3. 
schen gerecht sein, dann können auch die Juden Gerechtigkeit verlangen' (alte Bauersfrau Nordrhein-Westfalen); 'der Jude muß sich an den Staat halten, nicht an den jetzigen Besitzer' (Postbeamter mittleren Alters, ebda.) " usw $^{141}$. Die hier erkennbare gemeinsame Tendenz der Urteile läßt erneut darauf schließen, daß die deutsche Bevölkerung sich zu dieser Zeit in nicht unerheblichem Ausmaße in erster Linie selbst als Opfer betrachtete.

Die besondere Konzentration auf die Wiedergutmachung für die Juden zeigte sich auch daran, daß auf katholischer Seite gleichfalls für ein Abkommen mit Israel geworben wurde und die deutschen Verhandlungen in Wassenaar vereinzelt publizistisch unterstützt wurden. Rupert Angermair, Professor für Moraltheologie an der katholischen theologischen Hochschule in Freising, veröffentlichte eine ausführliche Stellungnahme zur "Wiedergutmachung an die Juden als moralische Pflicht". Der Restitution an die Juden müsse die Priorität vor allen anderen Leistungen ähnlicher Art zugesprochen werden. Dabei sah er nur eine einzige Ausnahme, nämlich die Wiederaufrüstung Deutschlands ${ }^{142}$. Auch Otto Küster und Franz Böhm, die beiden deutschen Delegationsleiter bei den Verhandlungen mit Israel und der Claims Conference 1952, standen dem Freiburger Kreis nahe und bezogen von dort moralische Rückendeckung für ihre Politik ${ }^{143}$. Allerdings verbanden katholische wie evangelische Kirche auch eigene Interessen mit den Israel-Verhandlungen: Beide versuchten in diesem Zusammenhang die Rückgabe des in Israel konfiszierten christlichen Missionseigentums zu erreichen ${ }^{144}$.

Verfolgt man die Entwicklung über die zeitliche Begrenzung dieser Untersuchung hinaus weiter, ergibt sich, daß sich seit Ende der fünfziger Jahre ein deutlicher Wandel dieser zwischen Indifferenz und intensivem partiellem Engagement wechselnden $\mathrm{Hal}-$ tung abzeichnete ${ }^{145}$. Vor allem die evangelische Kirche befaßte sich nun umso nachdrücklicher mit der Vergangenheitsbewältigung - ein äußeres Zeichen ist die Gründung der „Aktion Sühnezeichen“ 1958. Im Zuge dieses Wandels entfiel nicht nur die Verknüpfung mit dem christlichen Missionsanspruch gegenüber den Juden, sondern auch die Beschränkung der Perspektive allein auf die jüdischen Verfolgten wich allmählich einer differenzierteren Betrachtung des Verfolgungsspektrums. Bereits 1954 erschien in den Freiburger Rundbriefen erstmals ein Beitrag zur Problematik der verfolgten Zigeuner ${ }^{146}$. Die „Aktion Sühnezeichen" arbeitete gleichzeitig an der Versöhnung mit Israel, Polen und der Sowjetunion ${ }^{147}$. In den achtziger Jahren schließlich wurde insbesondere die evangelische Kirche geradezu zu einer Plattform zur Artikulation der Forderungen

141 Freiburger Rundbrief, Januar 1951, Nr. 10/11, „Schlagworte deutscher Judenfeindschaft und ihre Überwindung", S. 9 ff.

142 Rupert Angermair, Die Wiedergutmachung an die Juden als moralische Pflicht, in: Freiburger Rundbrief, August 1952, Nr. 17/18, S.3.

143 Siehe etwa die ausführliche Dokumentation anläßlich der Entlassung Küsters, Freiburger Rundbrief, September 1954, Nr. 25/28, S. 3-24.

144 Siehe dazu etwa Max Habicht (Vertreter und Rechtsberater des Lutherischen Weltbundes) an Bundesfinanzministerium, Auswärtiges Amt und Bundeswirtschaftsministerium, 2.9. 1952, PA/AA, II 244-13, Bd. 4; Aufzeichnung Janz (Auswärtiges Amt) für von Trützschler betr. Verhandlungen über das in Israel belegene Vermögen des Erzbischöflichen Stuhls in Köln, 17.3. 1953, PA/AA, II 244-13, Bd. 7.

145 Vgl. dazu Wolffsohn, Ewige Schuld?, S. $133 \mathrm{ff}$.

146 Vgl. Heinz Kraschutzki, Der Zigeuner, in: Freiburger Rundbrief, September 1954, Nr. 25/28, S. $25 \mathrm{f}$.

147 Vgl. dazu Aktion Sühnezeichen - Friedensdienste e.V., in: Der deutsch-israelische Dialog. Dokumentation eines erregenden Kapitels deutscher Außenpolitik, hrsg. v. Rolf Vogel, Teil III: Kultur, Bd. 6, München usw. 1989, S. 175-214. 
der sogenannten „vergessenen Opfer “ ${ }^{148}$. Erst vor kurzem engagierte sich Aktion Sühnezeichen als Träger einer Beratungsstelle für Verfolgte des Nationalsozialismus in Köln, die vor allem solchen Verfolgten helfen soll, die bis heute noch keine Entschädigung erhalten haben. Dies kann man auch als Bestätigung dafür ansehen, daß der Protestantismus insgesamt stärker auf aktuelle gesellschaftliche Trends reagiert im positiven wie im negativen.

\section{3. Öffentliche Meinung: „Was tun, wenn ein ganzes Volk bockt“}

Die Entwicklung der Wiedergutmachung in den ersten Nachkriegsjahren erfolgte ohne Rücksicht auf die öffentliche Meinung der deutschen Bevölkerung. Die Alliierten, die diesen Prozeß steuerten, hatten dazu allen Grund: Dort wo die Volksmeinung sichtbar oder - in seltenen Fällen - gezielt erfragt wurde, zeigte sich, daß sie einer Wiedergutmachung für die Opfer des Nationalsozialismus nicht allzu gewogen war ${ }^{149}$. Nach der Gründung der Bundesrepublik gewann der Faktor öffentliche Meinung zwar insgesamt ein größeres Gewicht im politischen Prozeß, doch blieb die Wiedergutmachung alles in allem ein Gebiet, auf dem Leistungen eher entgegen als wegen der öffentlichen Meinung beschlossen wurden ${ }^{150}$.

Eine erste breiter angelegte Untersuchung der Einstellungen der deutschen Bevölkerung zur Frage der Wiedergutmachung fiel gerade mit der Gründung der Bundesrepublik zusammen. Bei der vom Allensbacher Meinungsforschungsinstitut im August 1949 durchgeführten Befragung ${ }^{151}$ offenbarte sich bereits ein Phänomen, das auch für die meisten späteren Untersuchungen galt: In der Regel zielten die Fragen speziell auf die Einstellungen zur Wiedergutmachung für die Juden. Damit folgte die Meinungsstudie dem allgemeinen Trend, denn nach den ersten Nachkriegsjahren, in denen andere Verfolgtengruppen, namentlich die politisch Verfolgten, gleichfalls einen beträchtlichen Teil der Aufmerksamkeit auf sich gezogen hatten, fokusierte die Frage der Wiedergutmachung zusehends auf die jüdischen Verfolgten. Bei der Auswertung der Untersuchungen bleibt also zu bedenken, daß die Fragestellungen der Interviewer sozusagen selbst erst auf ihre historische Bedingtheit geprüft werden müssen.

In der genannten Erhebung des Allensbacher Instituts vom August 1949 wurde einer repräsentativen Auswahl von Bürgern der Bundesrepublik zunächst folgende Frage gestellt: „Glauben Sie, daß Deutschland gegenüber den noch lebenden deutschen Juden die Pflicht zur Wiedergutmachung hat?" 152 Hierauf antworteten 54 Prozent mit Ja und 31 Prozent mit Nein, 15 Prozent äußerten sich unentschieden. Gerade einmal gut die Hälfte der Befragten sprach sich also für eine - in der Frage nicht näher spezifizierte - Wiedergutmachung für die Juden aus, wobei wohlgemerkt nur

\footnotetext{
148 Vgl. etwa Die Bundesrepublik Deutschland und die Opfer des Nationalsozialismus. Tagung vom 25.-27. 11. 1983 in der Evangelischen Akademie Bad Boll, Protokolldienst 14/84, Bad Boll 1984.

$1+9$ Vgl. dazu etwa Drittes Kapitel, S. 100 f.

150 Für die spezielle Frage des Israel-Abkommens untersuchte dies Michael Wolffsohn, Das Wiedergutmachungsabkommen mit Israel: Eine Untersuchung bundesdeutscher und ausländischer Umfragen, in: Westdeutschland 1945-1955. Unterwerfung, Kontrolle, Integration, hrsg. v. Ludolf Herbst, München 1986, S. 203-218

151 Vgl. Elisabeth Noelle und Erich Peter Neumann, Jahrbuch der öffentlichen Meinung. 1947-1955, Allensbach 1956, S. 130.

152 Vgl. im folgenden ebenda.
} 
von den deutschen Juden die Rede war - ein Großteil der jüdischen Verfolgten fiel ohnehin nicht in diese Kategorie.

Eine zweite Frage zielte hingegen auf die Einstellungen gegenüber der Rückerstattung: „Wenn ein Nichtjude nach 1933 ein jüdisches Geschäft gekauft hat, und der frühere Besitzer verlangt nun die Rückgabe unter den gleichen Bedingungen: würden Sie sagen, seine Ansprüche bestehen zu Recht oder zu Unrecht?“ Hier, wo nun die praktischen Konsequenzen einer möglichen Wiedergutmachung den Befragten deutlicher vor Augen standen, fielen die Antworten bereits ein ganzes Stück zurückhaltender aus: Berechtigte Ansprüche, vorausgesetzt, das NS-Regime sei die eindeutige Ursache des Verkaufs, sahen 39 Prozent der Befragten. „Zu Unrecht" meinten 28 Prozent, „Kommt darauf an“ 25 Prozent, acht Prozent waren „unentschieden“. Natürlich war die Rückerstattung derjenige Prozeß, der die Interessen der deutschen Bevölkerung am unmittelbarsten traf: Anders als die Entschädigung, die finanziell über den Staat abgewickelt wurde, drohte sie jedem Bürger, der in der NS-Zeit jüdisches Eigentum erworben hatte, auf direkte Weise.

Mit größerer methodischer Raffinesse ging eine Meinungserhebung der amerikanischen Hohen Kommission vor, bei der 1.200 Bundesdeutsche im Oktober 1951 - also einen Monat nach Adenauers Erklärung zur jüdischen Frage vor dem Bundestag - zu ihrer Meinung bezüglich der Wiedergutmachung für die Juden und damit zusammenhängenden Themen befragt wurden ${ }^{153}$. Hier wurde nämlich die Frage nach der Wiedergutmachung für die Juden nicht isoliert, sondern in verschiedenartigen Kontexten gestellt. Den Befragten wurde zunächst eine Auswahl von fünf Gruppen, die durch den Krieg oder das Dritte Reich Schaden erlitten hatten, vorgelegt, worauf sie entscheiden konnten, welche davon Hilfe durch die Bundesrepublik erhalten sollten. Dabei sprachen sich immerhin 68 Prozent für die Gewährung von Hilfe an die Juden aus, 21 Prozent waren dagegen und 11 Prozent äußerten keine Meinung. Für sich genommen ein beachtlicher Wert, doch relativierte sich dieser durch die anderen Ergebnisse: Hilfe für Kriegswitwen und -waisen befürworteten nämlich 96 Prozent, bei Luftkriegsopfern waren dies 93 Prozent und bei Flüchtlingen und Vertriebenen aus dem Osten immerhin noch 90 Prozent.

Interessant an dieser Befragung ist, daß hier auch eine weitere Kategorie der Wiedergutmachungsansprüche berücksichtigt wurde, nämlich die Angehörigen derer, die im Zusammenhang des gescheiterten Attentats vom 20. Juli 1944 hingerichtet wurden. Hier sprachen sich 73 Prozent der Bevölkerung für Hilfe aus ${ }^{154}$, was vor dem Hintergrund einer verbreiteten mißbilligenden Stimmung gegegenüber dem Anschlag gesehen werden muß ${ }^{155}$. Immerhin lagen die Verschwörer damit aber noch ein Stück vor den Juden. Auch wenn diese Frage niemals gestellt wurde, so ahnt man zumindestens, wie

153 Siehe eine Zusammenfassung der Ergebnisse dieser Befragung in Report No. 113 (5 December 1951), "German Opinions on Jewish Restitution and some Associated Issues", in: Public Opinion in Semisovereign Germany. The HICOG Surveys, 1949-1955, hrsg. v. Anna J. Merritt u. Richard L. Merritt, Urbana u. Chicago, London 1980, S. 146; eine ausführlichere Fassung, die auf derselben Untersuchung basiert: „German Public Opinion Survey on Restitution“, AJC-Archiv, Blaustein Library, Restitution \& Indemnification, Germany - AJC.

154 German Public Opinion Survey on Restitution (Anm. 153).

155 Report No. 114, 5. 12. 1951, „The July 20 Plot on Hitler's Life: Does it Afford a Rallying Point for Rightist Groups?“, in: Merritt/Merritt (Hrsg.), HICOG Surveys, S. 147. Demnach billigten im Oktober $195138 \%$ der westdeutschen Bevölkerung das Attentat auf Hitler, während es $24 \%$ mißbilligten und $38 \%$ sich unsicher waren. 
die Ergebnisse ausgefallen wären, wenn man etwa Kommunisten, Zigeuner und andere Wiedergutmachungsaspiranten in den Fragenkatalog aufgenommen hätte.

Die Untersuchung rückte anschließend denjenigen Befragten, die sich positiv zur Wiedergutmachung für Juden ausgesprochen hatten, kritisch auf den Leib. Sie fragte man nun, welche Gruppe ihrer Meinung nach den ersten bzw. den letzten Anspruch auf Hilfe haben sollte. Dabei waren gerade zwei Prozent der Auffassung, daß Juden den ersten Anspruch haben sollten, während 17 Prozent die Juden auf den letzten Platz setzten ${ }^{156}$. Man muß nicht gleich Antisemitismus zur Erklärung heranziehen, wenn eine große Mehrheit der Deutschen lieber Kriegswitwen- und waisen als Juden entschädigen wollte. Gleichwohl ergab sich bei weiteren Fragen eine Korrelation zwischen der Wiedergutmachungsbereitschaft und der Einstellung gegenüber den Juden. Das eigentlich überraschende Ergebnis der Untersuchung war dabei aber nicht, daß zwei Drittel der Antisemiten sich gegen Wiedergutmachung für die Juden aussprachen (gegenüber etwas mehr als einem Drittel der Nicht-Antisemiten), sondern daß auch unter denen, die sich für die Wiedergutmachung aussprachen, beträchtliche antisemitische Neigungen existierten ${ }^{157}$. So erklärten 21 Prozent der Befragten, daß die Juden teilweise selbst dafür verantwortlich seien, was ihnen im Dritten Reich geschehen sei. Gleichwohl befürworteten 59 Prozent dieser Gruppe eine Wiedergutmachung für die Juden ${ }^{158}$. Wiedergutmachungsbereitschaft und antisemitische bzw. antijüdische Einstellungen bildeten also keine absoluten Gegensätze.

Die absoluten Prozentwerte für oder gegen Wiedergutmachung für die Juden muß man jedenfalls, wie deutlich wurde, mit großer Vorsicht handhaben. Aussagekräftiger sind hingegen die relativen Werte gegenüber anderen Geschädigtengruppen, da hier das „Volksempfinden“ vermutlich am deutlichsten zum Ausdruck kommt. Ohne Zweifel bewegten die Nöte der Kriegswitwen und -waisen, der Bombengeschädigten oder der Ostflüchtlinge und -vertriebenen die deutsche Bevölkerung wesentlich stärker als die der Verfolgten, zumal derer, die im Ausland lebten. Deshalb erklärten auch im August 195244 Prozent der Befragten, es sei überflüssig, daß Deutschland drei Mrd. DM in Waren an Israel als Wiedergutmachung bezahle, während sich weitere 24 Prozent zwar zustimmend äußerten, aber die Summe zu hoch fanden. Nur 11 Prozent sprachen sich hingegen für einen solchen Schritt aus ${ }^{159}$.

Die aufgeführten demoskopischen Ergebnisse belegen somit die in vielen Stimmungsberichten und Einzeläußerungen greifbare überwiegend ablehnende Haltung der bundesdeutschen Bevölkerung gegenüber der Wiedergutmachung. Besonders heftig trat diese dann in Erscheinung, wenn sie für den Einzelnen nicht nur indirekt als Belastung des Staatshaushalts, sondern, wie bei der Rückerstattung, direkt spürbar wurde. Natürlich spielte es eine erhebliche Rolle, daß die Frage der Wiedergutmachung für Opfer des Nationalsozialismus Anfang der fünfziger Jahre in einem Kontext mit

156 German Public Opinion Survey on Restitution (Anm. 153).

157 Ebenda.

158 HICOG Surveys, Report No. 113 (Anm. 153).

159 Noelle/Neumann, Jahrbuch der öffentlichen Meinung, 1947-1955, S. 130. $21 \%$ äußerten sich unentschieden. Als HICOG die Untersuchung wenige Monate später (im Dezember 1952) wiederholte, sprachen sich sogar 49\% der Befragten gegen das Abkommen aus gegenüber $26 \%$ Zustimmung. Vermutlich hatte sich nun ein Teil der vormalig Unentschiedenen erklärt. Siehe Report No. 167 (12 January 1953), „A Year End Survey of Rightist and Nationalist Sentiments in West Germany“, in: Merritt/Merritt (Hrsg.), HICOG Surveys, S. 197-199. Vgl, dazu auch Michael Wolffsohn, Untersuchung bundesdeutscher und ausländischer Umfragen, S. 206-212. 
zahlreichen dringenden sozialpolitischen Aufgaben stand, die überwiegend eine Folge des verlorenen Krieges waren.

Dabei wurde die Frage der Verantwortung für diese verschiedenartigen Schäden kaum zugunsten der Verfolgten beantwortet, wie demgegenüber etwa manche jüdische Organisationen, aber auch einige deutsche Persönlichkeiten forderten. Die Untersuchungen von HICOG Anfang der fünfziger Jahre ergaben wiederholt, daß mehr als die Hälfte der Westdeutschen sich weder dafür schuldig fühlte, was den Juden im Dritten Reich zugefügt worden war, noch dafür verantwortlich, diese Untaten wiedergutzumachen ${ }^{160}$. Es gibt keine Anhaltspunkte dafür, daß dieses Verhältnis gegenüber anderen Geschädigtengruppen günstiger ausfiel. Franz Böhm, langjähriger Kämpfer für die Wiedergutmachung in den Reihen der CDU, brachte diese Stimmungslage auf folgende Formel: „Schuldige an der Verfolgung hat es nicht gegeben, und wo steht geschrieben, daß Unschuldige eine Schuld wiedergutmachen sollen ? ${ }^{\text {“ } 161}$ Vor diesem Hintergrund waren natürlich alle Bestrebungen zur Verbesserung der Wiedergutmachung für Opfer des Nationalsozialismus außerordentlich schwierig, blies ihnen doch der Wind der öffentlichen Meinung frontal ins Gesicht. So klagte Franz Böhm 1952: „Was soll man tun, wenn ein ganzes Volk bockt. .. ? ${ }^{\text {162 }}$

\section{Klimawechsel}

\section{Abbau der Privilegien: „keinen Alte-Kämpfer-Mythos ... “}

Das politische Klima gegenüber den Verfolgten des Nationalsozialismus und der Wiedergutmachung hatte sich bereits wenige Jahre nach dem Kriegsende in auffälliger Weise gewandelt. Wilhelm Hoegner zufolge bestand 1950 „kein Zweifel daran, daß die Ansichten über eine notwendige Wiedergutmachung in den Jahren 1945 bis 1947 anders waren als heute "163. Dies machte sich auf verschiedene Weise bemerkbar. Noch bevor die eigentliche Wiedergutmachung, d.h. Entschädigung und Rückerstattung, überhaupt richtig in Gang gekommen war, wurden bestimmte Vergünstigungen, die den Verfolgten unmittelbar nach Kriegsende zur Erleichterung ihrer Rehabilitierung und gesellschaftlichen Wiedereingliederung eingeräumt worden waren, immer stärker in Frage gestellt. $\mathrm{Ob}$ es um Wohnungen, um Arbeitsplätze oder um die Regelungen für bezahlten Sonderurlaub ging, der Widerstand gegen Sonderrechte der Verfolgten, die ursprünglich meist auf Anordnungen der Militärregierung zurückgingen ${ }^{164}$, wurde überall größer.

Auf Grund solcher Bestimmungen hatte man unmittelbar nach Kriegsende vielfach Wohnungen und Wohnungseigentum ehemaliger nationalsozialistischer Aktivisten an Verfolgte verteilt bzw. im Zuge der politischen Säuberung freigewordene Arbeitsplätze mit solchen besetzt. Doch der in jener Zeit noch weithin akzeptierte Grundsatz, den

160 HICOG Surveys, Report No. 113 (Anm. 153), No. 167 (Anm. 159).

161 Franz Böhm, „Wie besiegen wir die Trägheit des Herzens? Gedanken zur Wiedergutmachung “, in: Frankfurter Allgemeine Zeitung, 13.1. 1955.

162 Zitiert nach Otto Küster, Grundlinien der deutschen Wiedergutmachung, in: Die Bundesrepublik Deutschland und die Opfer des Nationalsozialismus, Tagung in der Evangelischen Akademie Bad Boll, S. 89.

163 Zit. nach MdL Gabriel Mayer (CSU), Bayerischer Landtag, 1. Wp. 1946-1950, 177. Sitzung vom 6.9. 1950, Stenographische Berichte, S. 827.

164 Vgl. Zweites Kapitel, Abschnitt II. 3. 
Nationalsozialisten zu nehmen und den Verfolgten zu geben, wurde ausgerechnet im Zuge der Entnazifizierung zunehmend strittig. Bereits Mitte 1947 berichtete Otto Küster über die Verhältnisse in Württemberg-Baden, daß immer häufiger „Verfolgte, die in Wohnungen und Hausrat von Belasteten eingewiesen waren, nach dem Abschluß des Spruchkammerverfahrens in oft wenig erfreulicher Weise aus dem Besitz gesetzt werden, ohne daß es möglich ist, ihnen auch nur die nötigste Ausstattung anderweitig zu verschaffen " ${ }^{165}$. Ähnlich verhielt es sich in den anderen deutschen Ländern. Auch bei den Arbeitsplätzen wurde die Konkurrenz durch wieder rehabilitierte Ex-Nationalsozialisten immer stärker. So klagte der Vorsitzende der christlichen Hilfsstelle für rassisch Verfolgte nichtjüdischen Glaubens, M. Mayer, Anfang 1949 dem württembergbadischen Ministerpräsident Reinhold Maier: „Wir sind heute bereits wieder so weit, daß während überzeugteste Nazis, mit breitem Lächeln von den sicheren Warten bester Stellen aus, ihre umbuhlte Gunst verteilen, der rassisch Verfolgte seinen Arbeitsplatz wieder verlassen muß, um zu weichen vor den zurückkehrenden Nazis. “166

Auch in Bayern wurde dies zu einem Problem, wie 1949 von der Regierung vorgelegte Zahlen über Einstellungen und Entlassungen ehemaliger Parteigenossen und Verfolgter im öffentlichen Dienst zeigten: 6.239 nichtentlassenen Beamten standen 14.400 wiedereingestellte ehemalige Parteigenossen gegenüber. Bei den Angestellten standen 2.535 im Dienst verbliebenen Angestellten 9.527 wiedereingestellte Pg's gegenüber. Demgegenüber wurden 282 Verfolgte als Beamte eingestellt, von denen 17 wieder entlassen wurden; von 801 eingestellten Angestellten aus diesem Kreis wurde sogar 266 wieder gekündigt. Der SPD-Abgeordnete Josef Kiene zog daraus im Mai 1949 vor dem Bayerischen Landtag den Schluß, „daß die Personalpolitik darauf abgestellt ist, die ehemaligen Parteigenossen-Beamten wieder in Stellungen unterzubringen ${ }^{\text {“167. Diese }}$ Entwicklung, die nicht nur in Bayern, sondern auch in den anderen Ländern zu erkennen war, bewegte schließlich den amerikanischen Hohen Kommissar McCloy dazu, Adenauer zum Einschreiten aufzufordern. In einer Besprechung am 17. November 1949 teilte er ihm mit: „Wir beobachten jedoch die Tendenz gewisser Gruppen und gewisser sehr hoher Individuen, andere, die während der Naziperiode Widerstand geleistet haben, wo sehr schwer Widerstand zu leisten war, zu verdrängen “ ${ }^{168}$.

Die für die Betreuung der Verfolgten zuständigen Stellen versuchten ihr Möglichstes, um dieser Entwicklung entgegenzusteuern. So hatte Staatskommissar Auerbach noch Mitte 1948 vergeblich versucht, in Bayern ein „Gesetz zur Sicherung einer demokratischen Verwaltung“ zu initiieren. Dadurch sollte einerseits die Einstellung ehemaliger aktiver Nationalsozialisten und Militaristen in die Verwaltung verhindert und umgekehrt die der politisch und rassisch Verfolgten gefördert werden ${ }^{169}$. Doch kam dieser

165 Otto Küster, württemberg-badisches Justizministerium/Abteilung Wiedergutmachung, 3.7. 1947, Monatsbericht für Juni 1947, VVN/WB-Archiv, Wiedergutmachung-Entschädigungsgesetz. Siehe zur Wohnungsproblematik auch z.B. Schreiben der Nassauischen Heimstätte, GmbH, an den hessischen Innenminister Zinnkann, 13.1. 1950, HessHStA, Abt. 503, Nr. 473.

166 M. Mayer an R. Maier, 2. 1. 1949, BadWürtHStA, EA 1/920, Bü. 709.

167 Anfrage MdL Josef Kiene (SPD), Personalpolitik der Regierung, Bayerischer Landtag, 1. Wp. 1946-1950, 111. Sitzung vom 31.5. 1949, Stenographische Berichte, S. 192. Zum Vergleich: Aus dem Kreis der Flüchtlinge wurden 5.749 Beamte und 19.974 Angestellte eingestellt, von denen 4.947 wieder entlassen wurden.

168 Wortprotokoll der Besprechung der Hohen Kommissare mit Adenauer am 17.11. 1949, in: Adenauer und die Hohen Kommissare, Bd. 1: 1949-1951, hrsg. v. Hans-Peter Schwarz in Verbindung mit Reiner Pommerin, bearb. v. Frank-Lothar Kroll u. Manfred Nebelin, München 1989, S. $26 \mathrm{f}$.

169 Neue Zeitung, 10.6. 1948, „Dr. Auerbach reicht Gesetzentwurf ein“; Auerbach an Ehard, 29.5. 1948, BayHStA, MA 114263. 
Vorschlag, falls er jemals Chancen auf Erfolg gehabt haben sollte, zur Unzeit. Hier bestätigte sich nun, daß die „Entnazifizierung nach dem ,Befreiungsgesetz' nicht mehr eine Säuberung des öffentlichen Lebens von den Nazis, sondern eine Säuberung der

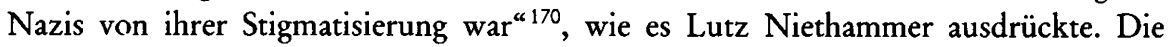
Fortsetzung einer Privilegierung der Verfolgten auf Kosten ehemaliger Nationalsozialisten führte so zu der Schwierigkeit, daß die im Zuge der Entnazifizierung betriebene Auflösung der gesellschaftlichen Kategorie "Ex-Nazi“" behindert wurde. Umgekehrt stieß aber auch die mögliche Verfestigung einer mit gewissen Privilegien verbundenen gesellschaftlichen Gruppe „Verfolgte des Nationalsozialismus" auf wachsenden Widerstand. Der Vorwurf lautete, man wolle keinen neuen "Alte-Kämpfer-Mythos“ haben ${ }^{171}$. Freilich sahen auch den Verfolgten nahestehende Kreise, daß die dirigistische Verteilung des Mangels keine endgültige Lösung sein konnte. Wie der hessische Staatssekretär Hermann Brill Anfang 1949 erklärte, war das „eigentliche Problem nur dadurch zu lösen, daß Wohnungen wieder aufgebaut und Möbel neu beschafft würden“172.

Im Zeichen dieser Kontroverse verhandelte der Bayerische Landtag Ende 1948 einen Entwurf für ein Gesetz zum Schutz der Arbeits- und Wohnungsverhältnisse ehemaliger Verfolgter des Nationalsozialismus. Finanzminister Friedrich Zietsch (SPD) unterstrich, man wolle damit dem entgegenwirken, daß diese auf dem Arbeitsmarkt wieder benachteiligt würden „und aus den Wohnungen in die sie eingewiesen wurden, verdrängt werden, damit die früheren politisch belasteten Inhaber wieder eingewiesen werden können “ ${ }^{173}$. Auch Wilhelm Hoegner beklagte, „daß die politisch Verfolgten der Jahre 1933 bis 1945 heute wieder Gefahr laufen, neuerdings verfolgt zu werden. Eine Reihe von Maßnahmen, die zugunsten der politisch Verfolgten in den Jahren 1945/46 getroffen wurden, würden jetzt wieder rückgängig gemacht. Man entziehe ihnen die Wohnungen und die Möbelbenutzung, die man ihnen zugestanden hatte. ${ }^{\text {“174 }}$ Der CSUAbgeordnete Josef Krempl kritisierte jedoch den Entwurf damit, daß „durch dieses Gesetz Leute betroffen werden, die gar nicht Nazi waren oder die zum mindesten wieder in die deutsche Volksgemeinschaft der Nichtnazis eingegliedert" worden seien. In anderen Worten: Die Rehabilitierung der ehemaligen Verfolgten gefährde die Rehabilitierung der Ex-Nationalsozialisten. Zugleich entgegnete er dem Vorwurf, letztere begünstigen zu wollen, er könne schließlich dafür eintreten, „daß die Denazifizierung doch endlich einmal aufhört ${ }^{\alpha 175}$. Damit verlieh Krempl einer weitverbreiteten Stimmung Ausdruck. Die Forderung nach Besserstellung der ehemaligen Verfolgten auf Kosten ehemaliger Nationalsozialisten stieß deshalb auf zunehmenden Widerstand jener, die ihrerseits den generellen Abschied von derartigen Etikettierungen verlangten.

Gleichwohl passierte der Entwurf als "Gesetz zum Schutz der Arbeits- und Wohn-

170 Lutz Niethammer, Problematik der Entnazifizierung in der BRD, in: Verdrängte Schuld, verfehlte Sühne: Entnazifizierung in Österreich 1945-1955, hrsg. v. Sebastian Meissl, München 1986, S. 25.

$171 \mathrm{Im}$ Zusammenhang der Auseinandersetzung um einen bezahlten Sonderurlaub für Verfolgte des Nationalsozialismus hieß es in den VVN-Nachrichten. Mitteilungsblatt der Vereinigung der Verfolgten des Naziregimes Württemberg-Baden, April 1949, „Um den Sonderurlaub für 1949“: „Aus gut unterrichteten Kreisen erfahren wir, daß die Gewährung des Zusatzurlaubes für unseren Personenkreis von den Unternehmern mit der Begründung abgelehnt wird, man wolle keinen „Alte-Kämpfer-Mythus“ züchten.“

172 Niederschrift über die außerordentliche Delegiertenkonferenz der VVN am 25.1. 1949 in Wiesbaden, HessHStA, Abt. 502, Nr. 2772 c.

173 Bayerischer Landtag, 1. Wp. 1946-1950, 96. Sitzung vom 16. 12. 1948, Stenographische Berichte, S. 407.

174 Ebenda.

175 Ebenda, S. $407 \mathrm{f}$. 
verhältnisse der aus religiösen, rassischen und politischen Gründen Verfolgten“ im Januar 1949 die parlamentarischen Hürden ${ }^{176}$. Doch in einer Entscheidung vom 17. November 1950 hob der Bayerische Verfassungsgerichtshof dieses Gesetz als verfassungswidrig auf. Er begründete diesen Schritt in erster Linie damit, daß der Gesetzgeber die Feststellung des von diesem Gesetz zu schützenden Personenkreises entgegen der bayerischen Verfassung einer nachgeordneten Verwaltungsbehörde, dem Bayerischen Landesentschädigungsamt, übertragen habe ${ }^{177}$. Den eigentlichen Kern des Problems bildete aber, daß die Privilegierung einer Sondergruppe innerhalb der Gesellschaft im Bereich des Wohnens und Arbeitens immer weniger akzeptiert wurde. So meldete die Süddeutsche Zeitung das Urteil der bayerischen Verfassungsrichter unter

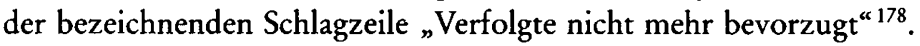

Aus dem Gleichheitsgebot der bayerischen Verfassung wie des Grundgesetzes resultiert in der Tat, daß es keine privilegierten Gruppen in der deutschen Gesellschaft geben solle. Doch wurde allzu schnell vergessen, welche kompensatorische Funktion die Sondervorrechte für die ehemaligen Verfolgten besaßen. Ihrer Natur nach waren diese bewußt als Übergangslösung konzipiert gewesen, doch erhebt sich die Frage, inwieweit sie ihre Aufgabe bis zum Beginn der fünfziger Jahre erfültt hatten. Eben dies bestritt Hoegner und klagte im September 1950 vor dem Bayerischen Landtag, daß „sich die früheren Nationalsozialisten ihres Besitzes erfreuen, während ihre Opfer vielfach ohne Entschädigung und zum Teil als Arbeitslose“ herumliefen ${ }^{179}$. So kommt man nicht umhin festzustellen, daß in aller Regel den ehemaligen Nationalsozialisten die gesellschaftliche Rehabilitierung schneller gelang als den vormalig Verfolgten.

\section{Gedenktage: Opfer des Nationalsozialismus und Opfer des Krieges}

Die veränderte Stellung der Verfolgten des Nationalsozialismus in der deutschen Gesellschaft an der Wende zu den fünfziger Jahren offenbarte sich auch im Bereich der politischen Symbolik. So hatten sich nach dem Ende des Dritten Reiches zunächst jährliche Gedenkveranstaltungen zu Ehren der Opfer der nationalsozialistischen Verfolgung eingebürgert. An diesen Feierlichkeiten beteiligten sich anfänglich durchwegs auch hochgestellte öffentliche Würdenträger. Typisch für den Ablauf dieser Veranstaltungen war etwa das Programm der 1. Dachau-Gedächtniskundgebung im Mai 1947: Dazu gehörte neben einem feierlichen Verdi-Requiem im Münchner Prinzregententheater unter anderem auch eine Ansprache des stellvertretenden Ministerpräsidenten

176 BayGVOBl, Nr. 3-4, 18. 1. 1949, S. 23.

177 Entscheidung des Bayerischen Verfassungsgerichtshof vom 17.11. 1950, in: BayGVOBI, Nr.31, 30.12. 1950, S. 263-266. Vgl. auch Mitteilungsblatt des Landesausschusses der politisch Verfolgten, Nr.49, 1. 12. 1950; Klaus-Günter Dietel, Die Arbeitsverhältnisse der Verfolgten des Nationalsozialismus - Zugleich ein Beitrag zur ideellen Wiedergutmachung, Diss. Würzburg 1966, S. 233.

$178 \mathrm{Vgl}$. Süddeutsche Zeitung, 21.11. 1950.

179 Bayerischer Landtag, 1. Wp. 1946-1950, 177. Sitzung vom 6.9. 1950, Stenographische Berichte, S. 827. Es bleibt allerdings schwierig, diesen häufig geäußerten zeitgenössischen Befund auch quantitativ zu verifizieren. Die amerikanische Militärregierung in Württemberg-Baden kam im Oktober 1949 aufgrund der Auswertung von Arbeitslosigkeitsstatistiken in ihrem Gebiet zu dem Ergebnis, daß keine organisierten Anstrengungen sichtbar seien, die Verfolgten zu diskriminieren. Vgl. James H. Campbell an Dep. Land Commissioner, 20. 10. 1949, IfZ-Archiv, Mf 260, OMGWB, 12/76-2/19. Die Dissertation von Klaus-Günter Dietel über die Arbeitsverhältnisse des Nationalsozialismus beschäftigt sich nur mit den juristisch-normativen Aspekten dieses Themas und enthält kein Material zu der Frage, wie sich die Beschäftigungsverhältnisse dieser Gruppe real verhielten. 
Hoegner ${ }^{180}$, der damit die Anerkennung und Verbundenheit des bayerischen Staates mit den ehemaligen Verfolgten demonstrierte.

Auch der "Tag der Opfer des Faschismus“, der seit 1946 überall in Deutschland und auch international am zweiten Sonntag im September begangen wurde, erfreute sich zunächst derartiger offizieller Wertschätzung. Auf der zu diesem Anlaß veranstalteten öffentlichen Kundgebung an der Münchner Feldherrnhalle am 14. September 1947 hielt der bayerische Innenminister Seifried eine Ansprache, in der er erklärte, den „heldenhaften Opfern und Verfolgten" gebühre "nicht nur unsere volle Anerkennung" und "größte Achtung" des ganzen Volkes, "sondern auch jegliche wirtschaftliche Sicherung ${ }^{\text {“ }}{ }^{181}$. Und in Württemberg-Baden beispielsweise beschloß der Ministerrat 1948 wie schon in den Vorjahren, daß der Gedenktag für die Opfer des Faschismus am 12. September durch die Regierung unterstützt werde, daneben sollte das Kultusministerium Schulfeiern am Vormittag anordnen und das Innenministerium an die Landräte und Oberbürgermeister Anweisungen erteilen, bei der Durchführung der Feiern mitzuhelfen ${ }^{182}$. Und auch 1949 ließ sich die bayerische Regierung wenigsten noch durch einen Staatssekretär bei der Gedenkveranstaltung am Tag der Opfer des Faschismus in München vertreten ${ }^{183}$.

Dieses offizielle Wohlwollen verflüchtigte sich an der Schwelle zu den fünfziger Jahren. Im Mai 1950 fragte Bundesinnenminister Gustav Heinemann bei der Interministeriellen Arbeitsgemeinschaft für Wiedergutmachungs- und Entschädigungsfragen nach, ob es nicht möglich sei, den Gedenktag für die Opfer des Faschismus „wegen gemeindlicher Feste oder lokaler Feiern im Interesse der Belebung des Fremdenverkehrs" in den Spätherbst zu verlegen. Die Arbeitsgemeinschaft wies diesen Vorschlag entschieden zurück und hielt am zweiten Sonntag im September fest ${ }^{184}$. Die im Gegenzug erhobene Aufforderung, die Bundesregierung möge von sich aus ein Gesetz einbringen, „das diesen Tag der Opfer des Faschismus als Bundestrauertag verkündet ${ }^{\text {“185 }}$, lief jedoch den Intentionen des Innenministers genau entgegen. Als die VVN für den 10. September die Durchführung solcher Veranstaltungen vorbereitete, versuchte Heinemann dem zuvorzukommen, wozu er in der Sitzung des Bundeskabinetts vom 11. August 1950 ,an die wiederholt erhobene Forderung (erinnerte), für die Kriegsopfer einen Gedenktag zu veranstalten. Die Länder seien der Meinung, daß man dieses Gedenken in Verbindung bringen sollte mit einem Verfassungsgedenktag und einem Gedenktag für die deutsche Einheit." Als Termin schlug er den ersten Sonntag im September vor ${ }^{186}$. Da Bundespräsident Theodor Heuss gegen eine solche Zusammenlegung eines „Totengedenktages und einer Verfassungsfeier“ war, fand schließlich statt dessen

180 Programm der 1. Dachau-Gedächtniskundgebung, 17./18.5. 1947, BayHStA, MA 114262.

181 14.9. 1947, Ansprache Innenminister J. Seifried anläßlich der öffentlichen Kundgebung an der Feldherrnhalle zum "Tag der Opfer des Faschismus“, BayHStA, MA 114263.

182 Niederschrift über die Sitzung des württemberg-badischen Ministerrats, 28. 7. 1948, BadWürtHStA, EA 4/ 001, Bü. 57a.

183 Ansprache von Staatssekretär Dr. Grieser zum „Tag der Opfer des Faschismus“ am 11.9. 1949 in München, BayHStA, MA 114263.

184 Protokoll über die Sitzung des Koordinierungsausschusses der 11 Länder am 25.5. 1950, BayMJ 1101a, H.4; Auerbach an Innenminister Gustav Heinemann, 27.5. 1950, abgedruckt in Mitteilungsblatt des Landesausschusses der politisch Verfolgten, Nr. 44, 1.7. 1950, "Gedenktag für die Opfer des Faschismus ${ }^{\star}$.

185 Auerbach an Heinemann, 27.5. 1950 (Anm. 184).

186 89. Kabinettssitzung am 11.8. 1950, in: Kabinettsprotokolle der Bundesregierung, Bd. 2, S.626. 
am 7. September 1950, dem Jahrestag der ersten Bundestagssitzung, eine Feierstunde statt $^{187}$.

Aber auch bei den Länderregierungen war die offizielle Bereitschaft zur Unterstützung des Gedenkens an die Verfolgten des Nationalsozialismus am Schwinden. Vor allem verringerte sich die Neigung, diese Geschädigtengruppe, wie in der ersten Nachkriegszeit häufig geschehen, gesondert herauszustellen. So sprach sich etwa der bayerische Ministerrat bei der Beratung darüber, wie man den sechsten Jahrestag der Befreiung des Konzentrationslagers Dachau begehen solle, gegen eine Kundgebung im Bayerischen Landtag aus ("nachdem auch keinerlei Einigung unter den politisch Verfolgten bestehe"). Zum Ausgleich wurde beschlossen, im Anschluß an eine Aufführung des "Fidelio" in der Staatsoper im Bayerischen Landtag eine kurze Gedenkfeier abzuhalten ${ }^{188}$.

Der Ablauf dieser Veranstaltung am 24. April 1951 ist höchst bezeichnend für die mittlerweile eingetretene Veränderung des Stellenwerts der Verfolgten im Bereich der öffentlichen Symbolik. Landtagspräsident Georg Stang hielt vor den bayerischen Volksvertretern eine Rede, in der er zunächst der rassisch, religiös und politisch Verfolgten des Nationalsozialismus gedachte, um dann diese „Gedächtnisstunde an die Opfer des Faschismus“ auszuweiten zu einem Gedenken an die im Zweiten Weltkrieg gefallenen Soldaten, an die Opfer des Bombenkrieges sowie die Flüchtlinge und Vertriebenen (bzw. mittlerweile „Heimatvertriebenen”). Und nachdem er die Wiedergutmachung für die Verfolgten angemahnt hatte, fuhr er fort: „Ein gleich hohes Maß an Fürsorge aber müssen auch die Bombengeschädigten erfahren ... und ebenso die Heimatvertriebenen “189. An diesem Beispiel zeigt sich, wie sehr die sozial- und gesellschaftspolitische Konkurrenz anderer Geschädigtengruppen nunmehr die Verfolgten in den Hintergrund drängte. Daß ausgerechnet der Jahrestag der Befreiung des Konzentrationslagers Dachau zur Gelegenheit genommen wurde, die Wiedergutmachungsansprüche der Verfolgten durch die Ansprüche der Kriegsgeschädigten sowie der Flüchtlinge und Vertriebenen zu relativieren, unterstreicht diesen Prozeß in aller Deutlichkeit.

Diese Entwicklung erfaßte alsbald auch den Gedenktag für die Opfer des Faschismus bzw. des Nationalsozialismus, wie er mittlerweile zumeist genannt wurde. Etwa seit 1951 gingen die Landesregierungen allgemein dazu über, diesen mit dem Volkstrauertag im November zusammenzulegen ${ }^{190}$. Bereits seit 1948 hatte es auf kommunaler oder regionaler Ebene wieder derartige Gedenkstunden zum Volkstrauertag gegeben, an dem in erster Linie der Opfer des Krieges gedacht wurde. Hier bestand eine Tradition seit der Weimarer Republik; im Dritten Reich war dieser Tag dann als Heldengedenktag gefeiert worden ${ }^{191}$. Die Vertreter der Verfolgten reagierten auf diese Quasi-Aufhebung des Tages der Opfer des Nationalsozialismus mit großer Bestürzung ${ }^{192}$.

187 Vgl. ebenda, Anm. 57.

188 Bayerischer Ministerrat, 2. 4. 1951, IfZ-Archiv, NL Hoegner, ED 120, Bd. 367.

189 Kundgebung zum Gedenken an die Opfer des Nationalsozialismus im Bayerischen Landtag, 2. Wp. 19501954, 19. Sitzung am 24.4. 1951, Stenographische Berichte, S. 480 . Vgl. dazu auch Mitteilungsblatt des Landesausschusses der politisch Verfolgten, Nr.53, Mai 1951, „Der 6. Jahrestag der Befreiung“.

190 Siehe etwa bayerischer Ministerrat, 21.8. 1951, IfZ-Archiv, NL Hoegner, ED 120, Bd. 369; hessische Ministerialdirigentenkonferenz, 24.9. 1951, HessHStA, Abt. 502, Nr. 2014.

191 Vgl. dazu Lutz Niethammer, Wer trauert um wen? Zu den Volkstrauertagen in der Bundesrepublik, in: Deutsche Rundschau, 11/1963, S.23f.

192 Vgl. etwa Mitteilungsblatt des Beirats beim Bayerischen Landesentschädigungsamt, Nr. 56, August/September 1951, "Totengedenktag“. 
Nunmehr wurde im Bereich der öffentlichen Symbolik zunehmend der Unterschied zwischen den Opfern des Nationalsozialismus und den Opfern des Krieges aufgehoben. Solche Tendenzen existierten schon länger: Bereits 1946 hatte, wie Konrad Adenauer berichtete, die CDU im Zonenbeirat der britischen Zone „zu einem kommunistischen Antrag auf Einrichtung eines Gedächtnistages für die Opfer des Faschismus einen Zusatzantrag gestellt, wonach auch der Opfer des Krieges gedacht werden soll, da diese Kriegsopfer ebenfalls Opfer des Nationalsozialismus seien “ ${ }^{193}$. Doch erst Anfang der fünfziger Jahre konnte sich diese Gleichbehandlung von Verfolgten und Kriegsopfern auf breiter Front durchsetzen: 1952 wurde der Volkstrauertag in allen Bundesländern einheitlich eingeführt und auf den zweiten Sonntag vor dem ersten Advent gelegt ${ }^{194}$.

Bei Gelegenheit der erstmaligen Durchführung des Volkstrauertages am 20. November 1952 hielt Bundespräsident Theodor Heuss eine Ansprache im Plenarsaal des Bundeshauses in Bonn, bei der er unter anderem ausführte: „Die Mal- und Mahnsteine wachsen - dies gilt den Opfern der Bombenangriffe, dies wächst an dem Rand eines Konzentrationslagers, dies steht auf dem und dem jüdischen Friedhof ... Hier die Folge der wüsten technischen Gewalt, dort die Folge der sittlichen Zerrüttung. Und wir stehen betreten, bedrückt vor beiden steinernen Zeugen. Es wird schon so sein: mancher wird murren, daß ich diese Opfer einer bösen Politik in einem nenne. " ${ }^{195}$ Hier kam nun geradezu programmatisch zum Ausdruck, daß letztlich alle gemeinsam Opfer des gleichen Schicksals, der selben „bösen Politik“ seien und somit auch das Gedenken den gleichen Stellenwert einnehmen sollte. Aus der damaligen Perspektive betrachtet war es dabei allerdings vor allem ungewöhnlich, ja mutig, daß Heuss in diese Reihe auch die Verfolgten des Nationalsozialismus aufnahm ${ }^{196}$.

In einem vieldiskutierten Aufsatz gab der Schweizer Philosoph Hermann Lübbe zu bedenken: „Daß man der Toten, die im Glauben an eine Sache gestorben sind, ineins mit den Menschen gedenkt, die weil sie dieser Sache im Wege standen, sterben mußten - das hat seinen unmittelbaren Ort im religiösen Lebenszusammenhang. “ ${ }^{197}$ Im irdischen Lebenszusammenhang bereitete dies aber vielfach große Pein. So schrieb Karl Marx, Herausgeber der Allgemeinen Wochenzeitung der Juden in Deutscbland, im November 1950 an Bundesjustizminister Dehler: „Ich habe längst aufgehört zu glauben, daß man einmal (sci. im Bundestag) eine Gedenkstunde einlegt, eine Gedenkstunde allerdings, die nicht zusammengelegt wird mit den Opfern des Krieges, weil es den Vertretern der Juden nicht zugemutet werden kann, möglicherweise neben den Hinterbliebenen eines SS-Mannes zu sitzen, der zuerst Mörder an Juden war, und dann Opfer

193 Konrad Adenauer im Protokoll über die Tagung des Zonenausschusses der CDU für die britische Zone vom 26. bis 28. Juni 1946 in Neuenkirchen/Kr. Wiedenbrück, in: Konrad Adenauer und die CDU der britischen Besatzungszone, 1946-1949. Dokumente zur Gründungsgeschichte der CDU Deutschlands, hrsg. v. d. Konrad-Adenauer-Stiftung, Bonn 1975, S. 157.

194 Vgl. Niethammer, Wer trauert um wen?, S. 23 ff.; Jan Hille, Volkstrauertag. Zum Wandel der politischen Kultur eines Gedenktages 1919-1972, Magisterarbeit, LMU München 1989, S. 90 ff.

195 "Unser Opfer ist Eure Verpflichtung: Frieden!“ Die Ansprache des Bundespräsidenten Theodor Heuss am Volktrauertag im Bundeshaus, in: Bulletin des Presse- und Informationsamtes der Bundesregierung, 20.11. 1952, Nr. 181, S. $1597 \mathrm{f}$.

196 Hille irrt hier insofern, als er der Auffassung ist, daß bei dieser Gelegenheit überhaupt erstmals auch die NSVerfolgten in das öffentliche Gedenken einbezogen wurden. Tatsächlich handelte es sich um zwei selbständige Stränge, die nunmehr zusammengelegt wurden. Vgl. ders., Volkstrauertag, S. $95 \mathrm{f}$.

197 Hermann Lübbe, Der Nationalsozialismus im deutschen Nachkriegsbewußtsein, in: Historische Zeitschrift 236 (1983), S. 591. 
des Krieges wurde. “198 Diese beiden Positionen bezeichnen die Extrempunkte in einer Diskussion, die die zentralen Fragen der sogenannten Vergangenheitsbewältigung betrifft $^{199}$.

Wo aber liegen die Ursprünge dieser Problematik? Zunächst wäre auf einen praktischen, politischen Zweck hinzuweisen. Die Gedenktage für die Opfer des Nationalsozialismus waren zu einem wichtigen Instrument der politischen Selbstdarstellung der VVN geworden. Im Zuge der zuvor beschriebenen Auseinandersetzung mit dieser Organisation lag es natürlich nahe, ihr dieses Podium zu nehmen. Weitere Gründe finden sich auf einer mehr grundsätzlichen Ebene: Die ständige Hervorhebung der Verfolgten des Nationalsozialismus erneuerte zwangsläufig auch stets die Frage nach der Verantwortung und Schuld. Demgegenüber konnte das Gedenken an die selbst erlittenen Opfer entlastend wirken: „Für Kriegstote, so hat man den Eindruck, wird die Erinnerung bei uns oft weit weniger aus Pietät denn aus der Absicht, Schuld aufzurechnen, wachgehalten“, schrieben Alexander und Margarete Mitscherlich $1967^{200}$. Dieser vielfach feststellbare Wunsch nach Aufrechnung der Opfer war allerdings zu Beginn der fünfziger Jahre von einem umfassenderen Bedürfnis überlagert: Darin, daß alle Seiten - die Verfolgten, die Verfolger, aber auch die in das Geschehen Hineingerissenen - als Opfer eines letztlich gemeinsam erlittenen Schicksals definiert wurden, drückte sich eine gesellschaftlich stark verbreitete Sehnsucht nach einem generellen Ende derartiger Polarisierungen aus.

\section{Versöhnung statt Entnazifizierung?}

Ein eindringliches Beispiel für den Wunsch nach solcher innenpolitischer Versöhnung lieferte der hessische Ministerpräsident Georg August Zinn (SPD) am 16. März 1950 vor dem Bundestag. Unter allgemeinem Beifall forderte er, die Gemeinsamkeit des Konflikts zwischen Vaterland und Menschheit „möge eine Brücke zwischen den Männern und Frauen des deutschen Widerstands und jenen sein, die durch die Männer und Frauen von Stalingrad repräsentiert werden" ${ }^{201}$. Die Forderung nach einem Ende des Gegenseitigen-Schuld-Aufrechnens und nach Versöhnung der verschiedenen Seiten gehörte in den Anfangsjahren der Bundesrepublik zu den Konstanten der politischen Diskussion. Dies ist eine Entwicklung, wie sie nach dem Übergang von Diktaturen in demokratische Gesellschaften häufig zu beobachten ist, was damit zusammenhängt, daß derartige Auseinandersetzungen zwangsläufig politisch und gesellschaftlich destabilisierend wirken. Damit einher geht freilich meistens in erster Linie die Forderung an die ehemaligen Opfer nach Verzicht auf Vergeltung sowie auf Wiedereingliederung derjenigen, die zuvor auf Seiten des Unterdrückungssystems standen.

So umwarben im ersten Bundestagswahlkampf 1949 bzw. in den Landtagswahlkämpfen 1950 nahezu alle Parteien die früheren NSDAP-Mitglieder und sprachen sich deshalb für die Beendigung der Entnazifizierung aus. Die CDU warb im Vorfeld der

198 Karl Marx an Thomas Dehler, 11.11. 1950, BA, B 126/12360.

199 Vgl. zu diesem Begriff Eckhard Jesse, „Vergangenheitsbewältigung“ in der Bundesrepublik Deutschland, in: Der Staat 26 (1987), S. 539-565.

200 Alexander und Margarete Mitscherlich, Die Unfähigkeit zu trauern. Grundlagen kollektiven Verhaltens, München 1967, S. 43.

201 Deutscher Bundestag, 47. Sitzung am 16. 3. 1950, Stenographische Berichte, Bd. 2, S. 1611. Siehe auch Arndt, Deutscher Bundestag, 229. Sitzung am 11.9. 1952, Stenographische Berichte, Bd. 13, S. 10433. 
Landtagswahlen in Schleswig-Holstein sogar mit einem Plakat, auf dem den ehemaligen Nationalsozialisten Schwarz-Rot-Weiß umrandet „Wiedergutmachung“ in Aussicht gestellt wurde, wie Bundestags-Rechtsaußen Adolf von Thadden ihr später höhnisch vorhielt ${ }^{202}$. Auch im Bundestag wurden seit Beginn der ersten Legislaturperiode zahlreiche Anträge zur Beendigung der Entnazifizierung eingebracht ${ }^{203}$. Der Ausschuß zum Schutze der Verfassung hatte schließlich über ein stattliches Bündel derartiger Anträge zu beraten. Auftragsgemäß arbeitete er eine Reihe von Maßnahmen aus, die dem Abschluß der Entnazifizierung dienen sollten. Doch erweiterte der Ausschuß das ursprünglich vorgesehene Programm um einen bedeutenden Punkt ${ }^{204}$ : Die Bundesregierung wurde nun zugleich auch aufgefordert, „den Entwurf eines Wiedergutmachungsgesetzes für alle im Bundesgebiet wohnenden politisch, rassisch oder religiös verfolgten Personen vorzulegen, das die Bestimmungen des im amerikanischen Besatzungsgebiet auf Länderratsbasis erlassenen zoneneinheitlichen Gesetzes von 1949 zeitgemäß für das gesamte Bundesgebiet fortbildet “205. Am 15. Dezember 1950 passierte die Vorlage in unveränderter Form den Bundestag ${ }^{206}$.

Hier wurde also noch einmal die politische Zusammengehörigkeit von Entnazifizierung und Wiedergutmachung zum Ausdruck gebracht, wenn auch in bemerkenswert veränderter Form: Hatte in den ersten Nachkriegsjahren ein breiter Konsens bestanden, daß die Wiedergutmachung Hand in Hand mit einer umfassenden politischen Reinigung gehen müsse, war dies unter dem Eindruck der immer mächtiger werdenden Forderung nach einem Ende solcher personeller Säuberungsbemühungen und nach weitestgehender Rehabilitierung der ehemaligen Nationalsozialisten zwangsläufig anders geworden. Dies mußte Auswirkungen für die Ansprüche der ehemaligen Verfolgten haben. Hatte das Paradigma der Zusammengehörigkeit von Entnazifizierung und Wiedergutmachung in der ersten Nachkriegszeit Ansätze einer Strukturreform impliziert, insofern als eine gewisse Verschiebung der gesellschaftlichen Balance zwischen ehemaligen Nationalsozialisten und Verfolgten zugunsten letzterer angestrebt worden war, wurde dies nun dem Hauptgesichtspunkt der „Versöhnung“ untergeordnet. Die strukturverändernden Momente wurden dabei ad acta gelegt. Versöhnung bedeutete aber auch, daß der individuelle Zusammenhang zwischen Opfern und Tätern bei der Wiedergutmachung nationalsozialistischer Verfolgung weiter zurücktrat, ein Prozeß, der ja bereits seit Ende der vierziger Jahre zu beobachten war.

Anfang der fünfziger Jahre fand dieser nun seinen weitgehenden Abschluß. Äußeres Zeichen dafür war, daß die Kosten der Entschädigung nun gänzlich auf die öffentlichen Haushalte übergingen. Entsprechend einer vielfach erhobenen Forderung haftete nun der Staat für die nationalsozialistischen Verbrechen, individuelle Verantwortung existierte nur noch im Bereich der Rückerstattung fort, wo sie weiterhin ein großes Ärgernis blieb - aber auch hier war ja bezeichnenderweise durch den Abschluß von Globalabkommen mit der JRSO ein Wandel eingetreten. Andererseits hatten deutsche Bevöl-

202 Deutscher Bundestag, 92. Sitzung am 18. 10. 1950, Stenographische Berichte, Bd. 5, S. 3436.

203 Ein Überblick zu diesen Anträgen findet sich im Mündlichen Bericht des Ausschusses zum Schutze der Verfassung (5. Ausschuß), - Deutscher Bundestag, 1. Wp. 1949-1953, Drucksache Nr. 1658, 24.11. 1950, Beilagen-Bd. 8.

204 Walter Menzel (SPD), Deutscher Bundestag, 92. Sitzung vom 18. 10. 1950, Stenographische Berichte, Bd. 5, S. $3432 \mathrm{f}$.

205 Mündlicher Bericht des Ausschusses zum Schutze der Verfassung (5. Ausschuß), - Deutscher Bundestag, 1. Wp. 1949-1953, Drucksache Nr. 1658, 24.11. 1950, Beilagen-Bd. 8.

${ }^{206}$ Deutscher Bundestag, 108. Sitzung am 15.12. 1950, Stenographische Berichte, Bd. 5, S. 4071. 
kerung und Politiker in ihrer Mehrzahl auch eine Kollektivschuld stets abgelehnt ${ }^{207}$. In der Tat kann Schuld außerhalb eines metaphysischen Deutungsrahmens immer nur individuell sein. Doch wurde nun für einige Zeit zugleich auch das intensive Fragen nach der individuellen Schuld in den Hintergrund gerückt, da dieses den erwünschten innenpolitischen Befriedungsprozeß störte. Einen theoretischen Ausweg formulierte Theodor Heuss, der am 7. Dezember 1949 in einer Rede anläßlich einer Feierstunde der Gesellschaft für christlich-jüdische Zusammenarbeit in Wiesbaden den Begriff der „kollektiven Scham“ prägte ${ }^{208}$. Darunter konnte sehr wohl auch eine kollektive Haftung gefaßt werden.

In dieses Bild lassen sich nun die gesammelten Bausteine einfügen: Die Thematisierung der Sonderrolle der Verfolgten des Nationalsozialismus durch eigene Gedenktage war ebenso wie die Fortführung bestimmter Vorrechte dieser Gruppe gegenüber ehemaligen Nationalsozialisten geeignet, die allgemein geforderte „Versöhnung“ zu stören. Das Reden von den Opfern evozierte auch ein Fragen nach den Tätern und störte damit zugleich die "gewisse Stille“, von der Hermann Lübbe als dem „sozialpsychologisch und politisch nötige(n) Medium der Verwandlung unserer Nachkriegsbevölkerung in die Bürgerschaft der Bundesrepublik Deutschland“ ${ }^{209}$ sprach. Lübbe zufolge war eben diese Stille bzw. „trügerische Ruhe“, wie es Peter Steinbach bezeichnete ${ }^{210}$, in den fünfziger Jahren die Voraussetzung dafür, daß neben Millionen von Flüchtlingen und Vertriebenen auch die große Zahl mehr oder weniger belasteter Ex-Nationalsozialisten insgesamt gesehen relativ reibungslos in die bundesrepublikanische Nachkriegsgesellschaft integriert werden konnte. Sie wird bei ihm damit zur Voraussetzung dafür erhoben, daß sich überhaupt ein demokratischer Grundkonsens sowie eine breite Akzep$\operatorname{tanz}$ der Bundesrepublik durchsetzen konnte. Zugleich legte Lübbe Wert darauf, daß das mit der Stille verbundene Schweigen nicht mit Vergessen oder gar Verdrängen gleichzusetzen sei und bezog damit Position in der Diskussion um die sogenannte „Vergangenheitsbewältigung“211.

Demgegenüber hatten etwa Theodor W. Adorno sowie Alexander und Margarete Mitscherlich in den sechziger Jahren dieses Schweigen als Nicht-Aufarbeiten bzw. Verdrängen interpretiert. Letztere entwickelten die These, daß sich in einem sozialpsychologischen Prozeß zur Vermeidung einer kollektiven Melancholie aufgrund des Verlustes des „Führers“ als kollektivem Ich-Ideal eine Derealisation der nationalsozialistischen Vergangenheit sowie auch die „Abwehr der Trauer um die zahllosen Opfer der Hitlerschen Agression“ herausgebildet hätten. Während die Motive des Nicht-RedenWollens von der nationalsozialistischen Vergangenheit bei den Mitscherlichs dabei im Unterbewußtsein angesiedelt wurden ${ }^{212}$, hatte Adorno bereits früher den Einwand erhoben, die „Tilgung der Erinnerung (sei) eher eine Leistung des allzu wachen Be-

\footnotetext{
207 Vgl. etwa Report No. 51 (2 April 1947), in: Anna J. Merritt u. Richard L. Merritt, Public Opinion in Occupied Germany, The OMGUS Surveys, 1945-1949, Urbana, Chicago, London 1970, S. 149.

$208 \mathrm{Vgl}$. auszugsweise Veröffentlichung der Rede in: Die Juden in Deutschland, 1951/52 - 5712, 1958/59 - 5719, Ein Almanach, hrsg. v. Heinz Ganther, Hamburg 1959, S. 11.

209 Lübbe, Nationalsozialismus im deutschen Nachkriegsbewußtsein, S. 585.

210 Peter Steinbach, Nationalsozialistische Gewaltverbrechen. Die Diskussion in der deutschen Öffentlichkeit nach 1945, Berlin 1981, S. 48.

211 Vgl. Lübbe, Nationalsozialismus im deutschen Nachkriegsbewußtsein, S. 587-589.

212 Mitscherlich, Unfähigkeit zu trauern, S. 34-36.
} 
wußtseins als dessen Schwäche gegenüber der Übermacht unbewußter Prozesse“213. Lübbe auf der einen Seite und Adorno bzw. den Mitscherlichs auf der anderen ging es dabei im Kern primär um die Stabilität bzw. die Legitimität des demokratischen Grundkonsenses der Bundesrepublik, wie er sich in den fünfziger Jahren herausgebildet hatte ${ }^{214}$.

Läßt sich somit bei der Frage nach der Funktion dieser gewissen Stille ein kleinster gemeinsamer Nenner finden, so resultieren die Differenzen also hauptsächlich aus der Frage nach den Kosten dieser Stille, wie sie etwa Gotthard Jasper und Lutz Niethammer erneut aufwarfen ${ }^{215}$. Gerade für den Zusammenhang der Wiedergutmachung ist diese von besonderer Bedeutung. Erfolgte die geforderte Versöhnung auch mit den Opfern des Nationalsozialismus oder nur einseitig zugunsten der ehemaligen Nationalsozialisten? Wurden die Verfolgten sozusagen auf dem Altar der gesellschaftspolitischen Integration und Stabilisierung der Bundesrepublik geopfert oder erhielten sie ihren gebührenden Anteil? Lübbe vertritt hier die These, daß sich zumindest als Norm „Verhältnisse symmetrischer Diskretion“ entwickelt hätten ${ }^{216}$. Dies wurde - meines Erachtens zu Recht - als wirklichkeitsfremd kritisiert ${ }^{217}$. Bereits Carlo Schmid vermißte diese Diskretion gerade auf Seiten der ehemaligen Nationalsozialisten: „Es ist doch allmählich so geworden, daß auch der ehemalige SS- und SD-Mann sich als Opfer des Nationalsozialismus zu betrachten beginnt “218, erklärte er am 22. Februar 1951 vor dem Bundestag. Als vorläufige Antwort kann man jedenfalls geben, daß die Wiedergutmachung für Verfolgte des Nationalsozialismus an der Wende zu den fünfziger Jahren im Lastenheft der Bundesrepublik eine weniger exponierte Stellung einnahm, als es in den Ländern unmittelbar nach Kriegsende der Fall gewesen war.

213 Theodor W. Adorno, Was bedeutet: Aufarbeitung der Vergangenheit, in: ders., Eingriffe. Neun kritische Modelle, Frankfurt a.M. 1963, S. 129.

214 Vgl. dazu auch Jesse, „Vergangenheitsbewältigung“, S. 551 f. u. 558.

215 Vgl. Gotthard Jasper, Wiedergutmachung und Westintegration. Die halbherzige justizielle Aufarbeitung der NS-Vergangenheit in der frühen Bundesrepublik, in: Herbst (Hrsg.), Westdeutschland 1945-1955, S. 185; Lutz Niethammer, Zum Wandel der Kontinuitätsdiskussion, ebenda, S. 79.

216 Vgl. Lübbe, Nationalsozialismus im deutschen Nachkriegsbewußtsein, S. 587.

217 Vgl. etwa Niethammer, Wandel der Kontinuitätsdiskussion, S. 79.

${ }^{218}$ Deutscher Bundestag, 120. Sitzung am 22. 2. 1951, Stenographische Berichte, Bd. 6, S. 4592. 